\title{
Behaviour of stainless steel plain channel section columns
}

$$
\text { Jelena Dobrić }{ }^{1} \text { Jovana Ivanović2 }{ }^{2} \text { Barbara Rossi }{ }^{3,4}
$$

${ }^{1}$ University of Belgrade, Faculty of Civil Engineering, jelena@imk.grf.bg.ac.rs

${ }^{2}$ University of Belgrade, Faculty of Civil Engineering, jovana.ivanovic@asmecbg.com

${ }^{3}$ University of Oxford, Department of Engineering Science, barbara.rossi@new.ox.ac.uk

${ }^{4}$ KU Leuven, Department of Civil Engineering, barbara.rossi@kuleuven.be

\begin{abstract}
In this paper, the structural stability of cold-formed stainless steel plain channel columns under axial compression is investigated. Reliable finite element models for channel section columns are first developed and validated against experiments conducted on stainless steel lipped channel specimens. This is followed by a parametric study in which columns made of austenitic, ferritic and duplex stainless steel are assessed. The considered cross-section classes and column lengths cover the entire range of global slenderness. The effects of material and geometrical nonlinearity are considered in the numerical analysis. The numerically generated data are then employed to evaluate the accuracy of the current European and Australian design codes EN 1993-1-4 and AS/NZS 4673 respectively, for predicting the flexural and flexural-torsional column buckling resistance. The results show a necessity to improve the current buckling curve used to predict the flexural buckling resistance of plain channel section columns, currently adopted in EN 1993-1-4, whose use may lead to unsafe predictions, especially for the austenitic grade.
\end{abstract}

Key-words: Stainless steel; Channel columns; Compression; Flexural buckling; Flexuraltorsional buckling; Buckling curve; Finite element modelling.

\section{Introduction}

Cold-formed steel (CFS) plain channels subject to axial compression are used in a significant number of structural applications, including lattice structures, façade columns, roof purlins, members of built-up columns, chords in the framing system of high-rise or long-span 
constructions, members of storage racks and greenhouses. CFS plain channel columns show three major buckling modes or a combination of those: local buckling, overall flexural buckling (FB), and flexural-torsional buckling (FTB) involving simultaneous lateral deflections about the major principal axis with a twist about the shear centre of the cross-section. The compressive capacity of slender channel cross-section, therefore affected by local buckling, is predominantly dictated by the ratio of web-to-flange width and the structural response is strongly governed by the interaction between the cross-section walls. For greater values of the web-to-flange ratio, local buckling of the web will govern the cross-section behaviour. For lower values of the ratio, slender flanges, which act as plates cantilevered out from the web, will be governing the local buckling behaviour [1].

Regarding overall buckling, the FTB mode is a characteristic of open cross-sections for which the centroid and shear centre do not coincide, hence decreasing the torsional rigidity of the section. For plain channel sections, this eccentricity only exists in the direction of the major principal axis; therefore the buckling in the symmetry plane is essentially independent of torsion [2]. That leads to the conclusion that the relevant buckling modes for plain channels are minor principal axis FB and FTB. Determining in advance which one will be the governing mode is not straightforward. One parameter of influence for assessing the global buckling mode is the web-to-flange width ratio: for greater ratios, the slenderness relative to the minor principal axis increases and the centroid and shear centre are brought closer to one another, leading to minoraxis FB. For lower values, the distance between the shear centre and centroid increases, which facilitates the initiation of FTB. The change of critical buckling modes (from FB to FTB) is more prominent in the case of fixed-end channel columns [3]. It has also been shown that, for plain channel section columns of the same length, as a consequence of the shift of the centroid of the effective cross-section, columns with fixed-ends exhibit greater overall capacity than columns with pinned-end conditions [4], [5]. Another influential parameter is the member 
slenderness: for the same cross-sectional geometry, increasing the members' unrestrained length increases the chances to get minor-axis FB.

The present paper studies cold-formed stainless steel (CFSS) plain channel section columns. Stainless steel is a chromium based alloy characterised by pronounced corrosion resistance and appealing surface finishes. According to their metallurgical microstructure, grades of stainless steel can be classified into essentially five main families: austenitic, ferritic, duplex (austeniticferritic), martensitic and precipitation hardening. Today, austenitic, ferritic and duplex families have been relatively often used as structural materials. Thin-walled sheets of austenitic grades, owing to the attractiveness of their surface finishes, have predominantly been used as cladding in buildings, while duplex grades, thanks to their enhanced mechanical properties combined with good corrosion resistance, have mostly been used in thicker structural load-bearing elements in corrosive environment. As structural material, ferritic grades are usually utilized in protected environment exposed to mild atmospheric conditions [6], [7], [8], [9].

Stainless steels exhibit clear differences in their mechanical properties compared to carbon steel. They are characterised by a distinct nonlinear stress-strain relationship compared to the elastic, perfectly-plastic material model for ordinary carbon steel, leading to a different treatment in most design standards. Nonlinear behaviour of stainless steel commences at low stress levels and the stress-strain curve is characterized by extended strain-hardening and the absence of yield plateau, which requires the equivalent yield stress, conventionally adopted as the $0.2 \%$ proof stress, to be used in the structural design [10], [11]. For CFSS plain channel section, the significant drop in strength in the intermediate cross-section slenderness range is not only caused by the element interaction but also by the inherent material nonlinearity [12]. Furthermore, the absence of flange end-stiffeners leads to their ineffectiveness for greater wall slenderness ratios, which, in turn, results in a shift of the effective cross-section centroid towards the web. This is of great importance for analyses involving local and overall buckling 
interaction, as the one presented in this paper.

\section{Outline of the paper}

The aim of this research is to assess the suitability of the current design models provided in the European and Australian standards for FB and FTB of cold-formed stainless steel (CFSS) plain channel columns. The finite element (FE) model presently used is firstly described. The models were calibrated and validated against experiments performed on CFSS lipped channels taken from previous studies. A parametric study is subsequently performed to generate reliable data over a wider range of members' non-dimensional slenderness and for three different stainless steel families. The current codified design models are then evaluated through the assessment of the safety factor $\gamma_{\mathrm{M} 1}$ and resistance factors $\phi_{\mathrm{c}}$.

\section{Literature review}

The theoretical and experimental observations on carbon steel channel columns serve as important benchmarks for a better understanding of the structural behaviour of stainless steel channel columns. Out of research conducted in the past concerning the behaviour of CFS plain channel sections, the following deserves to be mentioned here. The first published one from Mulligan et al. [13], involved experimental research conducted on 11 stub columns. The purpose of the research was to analyse the local buckling interaction between the cross-section walls. The authors report that the Effective Width Approach is applicable to the thin-walled plain channel stub columns considered in the paper. Ye et al. [14] performed experiments on 9 pinned-ended columns, investigating the interaction between local and FB. It was shown that the current design procedures proposed in EN 1993-1-3 [15], where interaction between local and overall buckling is accounted for, provide conservative predictions for CFS plain channel columns. The accuracy of the strength predictions is significantly increased if the method proposed in Annex E of EN 1993-1-5 [16], where the effective cross-section properties are based on the actual stress level instead of the yield strength, is used. Young and Rasmussen, 
[4], [5] explored the behaviour of press-braked members under compression, analysing the influence of different boundary conditions on the overall column behaviour. The material used was carbon steel G450 and a total of 22 specimens (14 fixed-ended and 8 pinned-ended) were tested. It was found that, for columns with the same effective length, fixed-ended column strengths were greater when the ultimate load exceeded the local buckling one. This is because fixed-ended conditions prevent additional bending to occur when the line of action of the internal force shifts due to local buckling. Moreover, it was concluded that local buckling shows the greatest impact on the strength of plain channel columns in the short and intermediate range of length. Moldovan [17] conducted tests on 16 stub columns and 19 columns, with the purpose of investigating the interaction of local, FB and FTB modes. The test results were found to be in good agreement with the theoretical predictions. To the best knowledge of the authors, the aforementioned researches constitute a summary of the currently available experimental research relevant to axially compressed carbon steel plain channels.

Tests and models of compressed stainless steel members conducted so far concerned, in majority, cold-formed hollow sections. The scientific literature on the behaviour of various types of open stainless steel cross-sections is today relatively scarce. Concerning the latter, the greatest part addresses the behaviour of lipped channel sections, and only a few of those concerned plain channel sections. In [18], Becque et al. conducted experiments on 29 pin-ended lipped channel stainless steel columns with the aim to analyse the interaction of local and overall flexural buckling. Three stainless steel alloys were considered: EN1.4301, EN1.4016 and EN1.4003. In [19], Rossi et al. examined the combination of distortional and overall flexuraltorsional buckling on cold-formed stainless steel lipped channel columns. A total of 21 columns made of EN1.4003 were tested. In [20] and [21], Lecce and Rasmussen investigated the effects of distortional buckling on cold-formed stainless steel lipped channels. A total of 19 tests were performed including 11 simple lipped channel columns and 8 lipped channel columns with 
intermediate stiffeners, made of EN1.4301, EN1.4016 and EN1.4003 grades. The results of [19], [20], [21] are used to calibrate the FE model which is presented in this paper.

Regarding plain channels, in essence two studies should be mentioned here: Dobrić et al. [12], who performed experiments on plain channel columns made of the austenitic grade EN1.4301, with a total of 4 stub column specimens with fixed-end conditions; and Kuwamura [22] who, among other types of cross-sections, performed experiments on 11 cold-formed stainless steel stub column specimens comprising plain channels made of austenitic EN1.4301 and EN1.4318 grades. None of these researches however covered overall (FB or FTB) buckling tests of slender stainless steel plain channel section columns.

Based on the content of the presented literature, it can be concluded that, the structural behaviour of CFSS is generally similar to the one of CFS equivalents. The major difference comes from the fact that stainless steel exhibits material non-linearity. On the one hand, the stress-strain behaviour characterised by gradual yielding leads to a reduction of the buckling strength of CFSS columns in the intermediate slenderness domain. On the other hand, the pronounced work-hardening associated with cold forming operations during manufacture positively affects the structural response of CFSS columns and increases the buckling strength in the low slenderness domain. In the high slenderness domain, CFSS and CFS columns exhibit quite similar behaviour, considering their approximately equal values of modulus of elasticity. Although not directly related to the topic of this paper, the following provides a broader view on what has been done in the past on the behaviour of both stainless and carbon steel channel sections subject to either compression, bending or a combination of both. Experiments and numerical analyses of built-up stainless steel channel section columns and beams are reported in [23], [24], [25] and in [26] respectively. With regard to single lipped and plain laser-welded channel members in bending, considerable results were obtained by Theofanous et al. in [27]. The combined effect of compression and minor axis bending on laser-welded stainless steel 
channels was analysed by Liang et al. in [28], [29]. Dizdar et al. in [30] carried out experiments on full-scale floor trusses fabricated from cold-formed steel channel sections tested under four point bending. It is also worth mentioning the following investigations on channels with perforated webs: in [31], Zhao et al. performed four point bending tests on cold-formed steel specimens; in [32], Yousefi et al. investigated the web crippling strength of cold-formed stainless steel plain channels.

\section{Existing design methods}

In this section, the European and Australian design codes for the design of stainless steel thinwalled members are summarised and the bases for assessing the behaviour of plain channel section columns are outlined. The common codes which are applicable to the design of stainless steel thin-walled structures are Eurocode 3: EN1993-1-4 [33] in conjunction with EN 1993-11 [34] and EN1993-1-3 [15], and AS/NZS 4673:2001 [35].

These codes request that the design strength of thin-walled sections, parts of which are susceptible to local buckling, should be determined on the basis of the Effective Width Approach. This approach accounts for local instability of parts of the cross-section in a manner which deems some parts ineffective and omits them from the calculation of the cross-sectional properties. The width of the plate elements comprised in the cross-section is reduced by introducing a reduction factor, which depends on the support conditions of the walls, loading conditions, yield strength of the material and width-to-thickness ratio of the walls. According to EN1993-1-4 [33], Clause 5.2.3, this reduction factor can be obtained as follows:

$$
\begin{array}{ll}
\rho=\frac{1}{\bar{\lambda}_{\mathrm{p}}}-\frac{0.188}{\bar{\lambda}_{\mathrm{p}}^{2}} \leq 1 & \text { for outstand elements with } \bar{\lambda}_{\mathrm{p}} \geq 0.748 \\
\rho=\frac{0.772}{\bar{\lambda}_{\mathrm{p}}}-\frac{0.079}{\bar{\lambda}_{\mathrm{p}}{ }^{2}} \leq 1 & \text { for internal elements with } \bar{\lambda}_{\mathrm{p}} \geq 0.651
\end{array}
$$

where: 
$\bar{\lambda}_{\mathrm{p}}=\frac{\bar{b} / t}{28.4 \varepsilon \sqrt{k_{\sigma}}}$

In Eq. (3), $\bar{b}$ is the notional widths of plane cross-section parts allowing for corner radius [15], $t$ is the plate thickness, $\varepsilon=\left[\left(235 / f_{\mathrm{y}}\right) \cdot(E / 210000)\right]^{0.5}$ is the material parameter and $k_{\sigma}$ is the plate buckling coefficient, taken as 0.43 for outstand elements and 4.0 for internal elements in uniform compression.

Clause 5.4 provides a procedure to determine the design buckling resistance of compression members, which is described by the following equations:

$$
\begin{array}{ll}
N_{\mathrm{b}, \mathrm{Rd}}=\chi A f_{\mathrm{y}} / \gamma_{\mathrm{M} 1} & \text { for Class } 1,2 \text { and } 3 \\
N_{\mathrm{b}, \mathrm{Rd}}=\chi A_{\mathrm{eff}} f_{\mathrm{y}} / \gamma_{\mathrm{M} 1} & \text { for Class } 4
\end{array}
$$

where $\chi$ is the non-dimensional buckling reduction factor, $A$ is the gross area of the crosssection, $A_{\text {eff }}$ is the effective area of the cross-section and $\gamma_{\mathrm{Ml}}$ is the partial safety factor.

For members with non-symmetric Class 4 cross-sections, allowance shall be made for the additional moment due to the eccentricity of the centroid of the effective cross-section with respect to the centroid of the gross cross-section.

The reduction factor $\chi$ is based upon the Perry-Robertson curve and can be obtained using Equation (6):

$$
\chi=\frac{1}{\phi+\sqrt{\phi^{2}-\bar{\lambda}^{2}}} \leq 1
$$

where $\phi$ is the operational parameter which can be calculated using the Equation (9), and $\bar{\lambda}$ is the relative slenderness:

$$
\begin{array}{ll}
\bar{\lambda}=\sqrt{\frac{A f_{\mathrm{y}}}{N_{\text {cr }}}} & \text { for Class } 1,2 \text { and } 3 \\
\bar{\lambda}=\sqrt{\frac{A_{\text {eff }} f_{\mathrm{y}}}{N_{\text {cr }}}} & \text { for Class } 4
\end{array}
$$


where $N_{\mathrm{cr}}$ is the elastic critical force for the relevant buckling mode, obtained based on gross cross-sectional properties.

The parameter $\phi$ is obtained in the following manner:

$\phi=0.5\left(1+\alpha\left(\bar{\lambda}-\bar{\lambda}_{0}\right)+\bar{\lambda}^{2}\right)$

where $\bar{\lambda}_{0}$ is the limiting non-dimensional slenderness and $\alpha$ is the factor which accounts for the imperfections.

The parameters $\alpha$ and $\bar{\lambda}_{0}$ depend only on the buckling mode and production process, they equal respectively 0.49 and 0.4 for FB of cold-formed open cross-sections, while for torsional and FTB, they equal 0.34 and 0.2 , respectively. However, research performed over the last years has led to the conclusion that the current EN 1993-1-4 buckling curves for cold-formed stainless steel sections may be optimistic and that there exists enough differences between the stainless steel families to afford a specific treatment in the design standard [6]. This fact was accounted for in the $4^{\text {th }}$ edition of the Design Manual for Structural Stainless Steel [6] for some types of cross-sections, but for CFSS channel columns made of austenitic, ferritic and duplex stainless steel, the parameters $\alpha$ and $\bar{\lambda}_{0}$ respectively equal 0.76 and 0.2 , irrespective of the alloy. But it has not been studied extensively and not yet been introduced in the current edition of EN 1993-1-4. It is the goal of the present paper to completely respond to the question for stainless steel plain channel section columns.

Local buckling of slender monosymmetric cross-section causes a shift of the centroid of the effective cross-section which consequently introduces secondary bending moment. Therefore, an initially centrically compressed column becomes a beam-column. This is however not the case for fixed-ended channel columns for which the shift in the line of action of the internal force is balanced by the shift in the line of action of the external force [5]. The effective width approach for local-overall interaction account for effective section properties in the calculation 
of the beam-column buckling stress. For stainless steel column with Class 4 cross-sections, the following equations (10), (11) and (12) from Clause 5.5 of EN 1993-1-4, take into account interaction effects between compressive axial load and uniaxial bending moment induced by the shift of the effective centroid.

For preventing premature buckling about the major axis:

$\frac{N_{\mathrm{Ed}}}{\left(N_{\mathrm{b}, \mathrm{Rd}}\right)_{\min }}+k_{\mathrm{y}}\left(\frac{N_{\mathrm{Ed}} e_{\mathrm{Ny}}}{W_{\text {eff,y }} f_{\mathrm{y}} / \gamma_{\mathrm{M} 1}}\right) \leq 1$

For preventing premature buckling about the minor axis (for members subject to lateraltorsional buckling):

$\frac{N_{\mathrm{Ed}}}{\left(N_{\mathrm{b}, \mathrm{Rd}}\right)_{\min 1}}+k_{\mathrm{LT}}\left(\frac{N_{\mathrm{Ed}} e_{\mathrm{Ny}}}{M_{\mathrm{b}, \mathrm{Rd}}}\right) \leq 1$

For preventing premature buckling about the minor axis:

$\frac{N_{\mathrm{Ed}}}{\left(N_{\mathrm{b}, \mathrm{Rd}}\right)_{\min }}+k_{\mathrm{z}}\left(\frac{N_{\mathrm{Ed}} e_{\mathrm{Nz}}}{W_{\mathrm{eff}, \mathrm{z}} f_{\mathrm{y}} / \gamma_{\mathrm{M} 1}}\right) \leq 1$

In the above expressions, $N_{\mathrm{Ed}}$ is the applied design value of the axial compression load; $e_{\mathrm{Ny}}$ and $e_{\mathrm{Nz}}$ are the shifts of the centroidal axes when the cross-section is subject to uniform compression; $\left(N_{\mathrm{b}, \mathrm{Rd}}\right)_{\min }$ is the smallest value of the design buckling load $N_{\mathrm{b}, \mathrm{Rd}}$ for the following four buckling modes: flexural buckling about the $y$ axis, flexural buckling about the $z$ axis, torsional buckling and torsional-flexural buckling; $\left(N_{\mathrm{b}, \mathrm{Rd}}\right)_{\min 1}$ is the smallest value of $N_{\mathrm{b}, \mathrm{Rd}}$ for the following three buckling modes: flexural buckling about the $z$ axis, torsional buckling and torsional-flexural buckling and $M_{\mathrm{b}, \mathrm{Rd}}$ is the design lateral-torsional buckling resistance. The interaction factors $k_{y}$ and $k_{\mathrm{LT}}$ can be obtained as follows:

$k_{\mathrm{y}}=1.0+2\left(\bar{\lambda}_{\mathrm{y}}-0.5\right) \frac{N_{\mathrm{Ed}}}{N_{\mathrm{b}, \mathrm{Rd}, \mathrm{y}}} \quad$ but $\quad 1.2 \leq k_{\mathrm{y}} \leq 1.2+2 \frac{N_{\mathrm{Ed}}}{N_{\mathrm{b}, \mathrm{Rd}, \mathrm{y}}}$ 
$k_{\mathrm{LT}}=1.0$

For cold-formed cross-sections, according to EN 1993-1-3 [15] an alternative interaction formula may be used:

$\left(\frac{N_{\mathrm{Ed}}}{N_{\mathrm{b}, \mathrm{Rd}}}\right)^{0.8}+\left(\frac{M_{\mathrm{Ed}}}{M_{\mathrm{b}, \mathrm{Rd}}}\right)^{0.8} \leq 1.0$

in which $M_{\mathrm{Ed}}$ includes the effects of shifts of neutral axis, if relevant.

According to AS/NZS 4673:2001 [35], for uniformly compressed members, the effective width of the cross-section shall be determined in accordance with Clause 2.2.1.2, where the effective widths are obtained using the following equations :

$$
\begin{array}{ll}
\text { For } \bar{\lambda}_{\mathrm{p}} \leq 0.673 & b_{\mathrm{e}}=\bar{b} \\
\text { For } \bar{\lambda}_{\mathrm{p}}>0.673 & b_{\mathrm{e}}=\rho \bar{b}
\end{array}
$$

where $b$ is the flat width of element excluding radii and $\rho$ is the effective width factor, calculated as follows:

$$
\rho=\frac{\left(1-\frac{0.22}{\bar{\lambda}_{\mathrm{p}}}\right)}{\bar{\lambda}_{\mathrm{p}}} \leq 1
$$

where $\bar{\lambda}_{\mathrm{p}}$ is the slenderness ratio of the plate element and can be obtained via equation (3).

According to Clause 3.4.1 of AS/NZS 4673:2001 [35], the design compressive axial force shall be calculated as a product of $\phi_{\mathrm{c}}$ and $N_{\mathrm{c}}$, where $\phi_{\mathrm{c}}$ is the strength reduction factor for members in compression and $N_{\mathrm{c}}$ is defined as follows:

$$
N_{\mathrm{c}}=A_{\mathrm{e}} f_{\mathrm{n}}
$$

where $A_{\mathrm{e}}$ is the effective area calculated at buckling stress $f_{\mathrm{n}}$, which is the least of the flexural, torsional and flexural-torsional buckling stress.

In order to account for the non-linear material law of stainless steel, the AS/NZS Specification 
proposes an iterative design procedure employing the tangent-modulus approach.

For sections not subject to torsional or FTB, the FB stress is defined in as:

$$
f_{\mathrm{oc}}=\frac{\pi^{2} E_{\mathrm{t}}}{(k l / r)^{2}} \leq f_{\mathrm{y}}
$$

where $E_{\mathrm{t}}$ is the tangent modulus in compression corresponding to the buckling stress, $k$ is the effective length factor, $l$ is the unbraced length of the member and $r$ is the radius of gyration of the gross cross-section. A rather similar expression is provided in ASCE 8-02 [36], Clause 3.4.1, except that $f_{\mathrm{oc}}$ is regarded as $f_{\mathrm{n}}$, which seems more sensible in terms of nomenclature and avoids possible confusion.

As an alternative to the iterative method, an explicit design procedure is also proposed. In this procedure, the following expression for the $\mathrm{FB}$ stress $f_{\mathrm{n}}$ is given:

$$
f_{\mathrm{n}}=\frac{1}{\phi+\sqrt{\phi^{2}-\lambda^{2}}} \leq 1
$$

where:

$$
\begin{aligned}
& \phi=0.5\left(1+\eta+\lambda^{2}\right) \\
& \eta=\alpha\left(\left(\lambda-\lambda_{1}\right)^{\beta}-\lambda_{0}\right) \\
& \lambda=\left(\frac{k l}{r}\right) \sqrt{\frac{f_{\mathrm{y}}}{\pi^{2} E_{0}}}
\end{aligned}
$$

which is in essence the same as in the European code except that the slenderness is here expressed in terms of the buckling length $k l$ and the radius of gyration $r$ rather than the critical load $N_{c r}$ as in equation (7).

For austenitic, ferritic and duplex grades, the parameters $\alpha, \beta, \lambda_{0}$ and $\lambda_{1}$ are given in Table 1 . These generic equations are based on [37] and [38]. Note that the parameters included in equation (23) do not bear the same significations as the ones in equation (9). The parameter $\eta$ 
in the Australian code should be compared to $\alpha\left(\bar{\lambda}-\bar{\lambda}_{0}\right)$ in the European one, where $\lambda_{0}$ is the plateau length. In the next sections of this paper, the parameters provided in Table 1 will be denoted with the subscript AUS: $\alpha_{\text {AUS }}$ and $\lambda_{0, \text { AUS }}$.

For sections subject to torsional buckling, $f_{\mathrm{n}}$ is defined as follows:

$$
f_{\mathrm{n}}=\sigma_{\mathrm{t}}=\left(\frac{1}{A r_{0}^{2}}\right)\left(G_{0} J+\frac{\pi^{2} E_{0} C_{\mathrm{w}}}{\left(k_{\mathrm{t}} l_{\mathrm{t}}\right)^{2}}\right)\left(\frac{E_{\mathrm{t}}}{E_{0}}\right)
$$

where $A$ is the gross cross-sectional area, $r_{0}$ is the polar radius of gyration about the shear centre, $G_{0}$ is the initial shear modulus, $J$ is the torsional constant, $E_{0}$ is the initial elastic modulus, $C_{\mathrm{w}}$ is the warping constant, $k_{\mathrm{t}}$ is the effective length factor for twisting and $l_{\mathrm{t}}$ is the unbraced length for twisting.

For sections subject to $\mathrm{FTB}, f_{\mathrm{n}}$ shall be adopted as the lesser of $f_{\mathrm{n}}$ calculated according to Eq. (26) and the critical FB stress obtained in accordance with Clause 3.4.2 of AS/NZS 4673:2001 [35].

$$
f_{\mathrm{n}}=\frac{1}{2 \beta}\left(\sigma_{\text {ey }}+\sigma_{\mathrm{t}}-\sqrt{\left(\sigma_{\text {ey }}+\sigma_{\mathrm{t}}\right)^{2}}-4 \beta \sigma_{\text {ey }} \sigma_{\mathrm{t}}\right)
$$

where $\sigma_{\text {ey }}$ is the flexural major-axis buckling critical stress, while the meaning of the factor $\beta$ is essentially the same as in EN1993-1-3 [15].

It should be emphasized that there is a discrepancy between Eq. (26) and the expression for the critical FTB stress provided in ASCE 8-02 [36], Clause 3.4.3, which has the following form:

$$
F_{\mathrm{n}}=\frac{1}{2 \beta}\left(\sigma_{\text {ey }}+\sigma_{\mathrm{t}}-\sqrt{\left(\sigma_{\text {ey }}+\sigma_{\mathrm{t}}\right)^{2}-4 \beta \sigma_{\text {ey }} \sigma_{\mathrm{t}}}\right)
$$

There has probably been a typing error and Eq. (26) should be adequately corrected by putting the second term $4 \beta \sigma_{\mathrm{ey}} \sigma_{\mathrm{t}}$ under the square root, as in Eq. (27).

According to Clause 3.5 of AS/NZS 4673:2001 [35], the design axial compressive load $N^{*}$ and 
the design bending moments $M_{\mathrm{y}}^{*}$ and $M_{\mathrm{z}}^{*}, y$ and $z$ being the major and the minor principal axes, respectively, shall satisfy the following equations:

$$
\begin{aligned}
& \frac{N^{*}}{\phi_{\mathrm{c}} N_{\mathrm{c}}}+\frac{C_{\mathrm{my}} M_{\mathrm{y}}^{*}}{\phi_{\mathrm{b}} M_{\mathrm{by}} \alpha_{\mathrm{ny}}}+\frac{C_{\mathrm{mz}} M_{\mathrm{z}}^{*}}{\phi_{\mathrm{b}} M_{\mathrm{bz}} \alpha_{\mathrm{nz}}} \leq 1,0 \\
& \frac{N^{*}}{\phi_{\mathrm{c}} N_{\mathrm{s}}}+\frac{M_{\mathrm{y}}^{*}}{\phi_{\mathrm{b}} M_{\mathrm{by}}}+\frac{M_{\mathrm{z}}^{*}}{\phi_{\mathrm{b}} M_{\mathrm{bz}}} \leq 1,0
\end{aligned}
$$

Where $N_{\mathrm{c}}$ is the nominal member capacity of the member in compression, $M_{\mathrm{by}}$ and $M_{\mathrm{bz}}$ are the nominal member moment capacities about the major and the minor principal axes, respectively, $N_{\mathrm{s}}$ is the nominal section capacity in compression, $\alpha_{\mathrm{ny}}$ and $\alpha_{\mathrm{nz}}$ are the moment amplification factors obtained as $1-\left(N^{*} / N_{\mathrm{e}}\right)$, where $N_{\mathrm{e}}$ is the elastic buckling load about the minor $\left(N_{\mathrm{ez}}\right)$ and the major $\left(N_{\mathrm{ey}}\right)$ axis, $C_{\mathrm{my}}$ and $C_{\mathrm{mz}}$ are the coefficients for unequal end moments, $\phi_{\mathrm{c}}$ and $\phi_{\mathrm{b}}$ are the strength reduction factors for compression and bending, respectively.

\section{Finite element modelling and validation}

This Section describes the numerical procedures employed to develop reliable FE models and to generate a large series of numerical data in order to assess the appropriateness of the existing codified procedures for the design of CFSS channel columns.

In the absence of experimental data on the overall buckling behaviour of slender CFSS single channel columns, the experiments on CFSS lipped channel columns with fixed ends from Rossi and Rasmussen [19] and Lecce and Rasmussen [20], [21], were used to validate the model. The papers include details of the experimental approach, the observed structural behaviour and measured data such as the experimentally obtained ultimate buckling loads. The numerical simulations of the mentioned experiments are described in [39]. ABAQUS FE software package was used [40]. Linear Buckling Analysis (LBA) was employed to predict the critical buckling mode shapes used to model the distributions of the initial geometric imperfection and allow for 
a realistic incremental non-linear procedure. The geometrically and materially non-linear analysis (GMNIA) was carried out as quasi-static with the dynamic explicit solver.

Numerical results were generated and compared against the ten experiments of Rossi and Rasmussen [19] and the four experiments of Lecce and Rasmussen [21]. In order to model the experiment of [19], the measured geometry was modelled using S4R shell elements with reduced integration and finite membrane strain. A square element with a size of $2 \mathrm{~mm}$ (approximately equal to 1.5 times the cross-section thickness) was used to discretise the flat and corner parts of the modelled cross-section. To model the supporting conditions of the specimens during the tests, the end plates of the testing machine were modelled as $2 \mathrm{D}$ rigid bodies. Four hexahedral solid elements C3D8R were introduced to simulate the guiding plates placed along the outside and inside cross-section perimeters during the experiment. Contact conditions between the guiding plates and the end-plates of the testing machine were defined through tie constraints on the joining surfaces. The surface-to-surface general contact was selected to take into account the interactions between the surfaces of the end cross-sections and the guiding plates.

The same approach was used to model the specimens' boundary conditions in [21] with contact conditions between the column's end cross-sections and the end plates defined via tie constraints at the joining surfaces, although there was no additional plate preventing warping of the end cross-sections.

Two reference points were defined at the centroid of the top and bottom bearing plates, coinciding with the centroids of the specimens' end cross-sections. Displacement controlled analysis was used and a nodal displacement of one reference point was prescribed. Typical geometry, boundary conditions and mesh are shown in Fig. 1. 
(a) Calibrated FE model of Rossi and Rasmussen's experiment [19]

(b) Calibrated FE model of Lecce and Rasmussen's experiment [21]

Fig. 1 Geometry, boundary conditions and mesh of the calibrated FE models.

The base material of all specimens in [19] and [21] is the ferritic stainless steel grade EN 1.4003, and the austenitic stainless steel grade EN 1.4301, respectively. Plasticity with isotropic hardening was used with the modulus of elasticity $E=200000 \mathrm{~N} / \mathrm{mm}^{2}$, and Poisson's ratio $v=$ 0.3. To account for the nonlinear material law, the analytical stress-strain curves for the flat and corner parts of the press-braked sections were defined by employing the modified RambergOsgood material model [11] using key material properties obtained via tensile coupon tests of the flat and corner portions. The material behaviour of the corner parts was confined to the corner region following the reasoning that there are no significant strength increases beyond the curved portions in press-braked sections [41].

The inputted geometric imperfections are linear combinations of sine wave functions which reflect the eigenmode shapes obtained via LBA. Four shape distributions of geometric imperfections were considered: a sine wave (bow) imperfection in the plane perpendicular to the minor principal axis, a twist imperfection, a local imperfection and a distortional geometric imperfection. The imperfection amplitudes matched the measured ones. Considering that a number of investigations such as [42], [43], indicate that residual stresses due to cold working insignificantly impact the overall behaviour of stainless steel thin-walled compressed members, the residual stresses induced by the manufacturing process were not included in the FE models. The accuracy of the FE models was assessed by comparing the key results to the experimental ones i.e. ultimate buckling loads and full load-deflection curves. The numerical failure modes including distortional buckling and minor axis FB for low and intermediate column slenderness and flexural-torsional mode for high column slenderness match the experimental ones [19]. Fig. 2 gives a qualitative comparison of the distortional buckling mode occurring in the specimen 
with a length of $900 \mathrm{~mm}$ against the FE prediction.

Fig. 2 FEM and experimental [19] buckling pattern of lipped channel column with a length of 900 $\mathrm{mm}$.

Excellent matching is achieved for the ultimate buckling load $N_{\mathrm{b}, \mathrm{u}}$ for all experiments. The average value of the FEM-to-experiments ultimate load ratio $N_{\mathrm{b}, \mathrm{u}, \mathrm{FEM}} / N_{\mathrm{b}, \mathrm{u} \text {,exp }}$ equals 1.01 and the coefficient of variation $(\mathrm{CoV})$ is $1.81 \%$, as shown in Table 2 .

Fig. 3 compares the experimental load versus end-shortening curves for a range of four selected columns with the equivalent curves obtained through FE modelling.

Fig. 3 Load versus end shortening - Comparison between experiments [19] and FEM results. As for the previous experimental programme, the average value of the FEM-to-experimental ultimate load ratio for the experiments included in [21] is 1.00 with a CoV of $0.95 \%$ (see Table $3)$.

Fig. 4 compares the FE load versus end-shortening curves with the corresponding experimental ones. The numerical failure modes show inward or outward distortional buckling and correspond to the experimental ones (see Fig. 5).

Fig. 4 Load versus end shortening recorded during the experiments of [21] compared to the FEM results.

Fig. 5 FEM and Experimental [21] buckling pattern of lipped channel column.

In general, quite good agreement is achieved in terms of overall shape, initial stiffness, deformation capacity and ultimate resistance.

In the formulation of design criteria of structures for which initial imperfection effects can be significant, the permissible fabrication and erection tolerances prescribed in the appropriate codes should be used as the basis of stability checks. To assess the sensitivity of the column's 
compressive capacity to several combinations of imperfection modes and amplitudes, the following imperfection sensitivity study was performed. Four different imperfections were considered: flexural (bow), local, distortional and twist deviations. The magnitude of the imperfection, based on LBA corresponding to the eigenmode shape, was successively chosen equal to $\omega_{0}= \pm t$, for a leading distortional imperfection in agreement with [44]; $\omega_{0}= \pm d / 100$ for a leading local imperfection, in accordance with the cross-section tolerance given in EN 1090-2 [45]; $\omega_{0}= \pm d / 50$ for a leading twist imperfection, based on Annex C of EN 1993-1-5 [16] and $\delta_{0}= \pm L / 1000$ for flexural imperfection that corresponds to $80 \%$ of the fabrication tolerances given in EN 1090-2 [45]. Following the clause C.5.(5) of EN 1993-1-5 [16], one of the cross-section imperfections was taken as the leading imperfection and the others were taken as the accompanying imperfections whose amplitudes were reduced by a factor 0.7 . It was found that the pattern using a leading local imperfection with an amplitude of $d / 100$ in the low slenderness domain, a distortional imperfection of $t$ in the intermediate slenderness domain, and a twist imperfection of $d / 50$ in the high slenderness domain, led to the best agreement with the experimental results.

\section{Numerical parametric study}

An extensive FE parametric study was conducted including a wide range of overall and crosssection slenderness to meet different performance levels and to establish a calculation model for the design buckling resistance $N_{\mathrm{b}, \mathrm{Rd}}$ of CFSS plain channel columns. In total 14 different plain channel cross-sections dimensions were selected providing both slender and non-slender cross-sectional behaviour. The geometrical proportions of the cross-section walls satisfy the conditions of Table 5.1 of EN 1993-1-3 [15]. The wall thicknesses range between 2 and 6 mm, as provided in Table 4, with the used dimensional code for the cross-section geometry as shown in Fig. 6. Pinned-ended columns were studied addressing their FB capacity about their minor and major principal axes and their FTB capacity. 
Shell elements S4R with a size equal to $1.5 t$, where $t$ is the cross-section thickness, were used to discretise the cross-section and the same size of shell elements was selected along the length of the columns. Reference points were set at the centroids of the columns' end cross-sections and kinematically constrained to the end cross-section surfaces. Displacement control was used to apply the compressive displacement to the reference point in the loading zone. The geometry, mesh and boundary conditions of one typical FE model are presented in Fig. 7.

Fig. 6 Designations of cross-section geometry.

Four stainless steel material models were presently considered: austenitic grade in cold-rolled condition, austenitic grade in hot-rolled condition, ferritic grade and duplex grade. The key material properties are based on Dobrić's tests (EN 1.4301) [12], Lecce's tests (EN 1.4301) [21], Rossi's tests (EN 1.4003) [19] and Saliba and Gardner's tests (EN 1.4162) [46]. Strength enhancement due to work hardening in the corner regions was considered according to Rossi's predictive model [41]. The Modified Ramberg-Osgood material model [11] was used to model the stress-strain curves. Table 5 and Table 6 provide the material parameters included in the FE models for the flats and corners of the studied cross-sections: the yield strength $f_{\mathrm{y}}$ taken as the $0.2 \%$ proof strength, the ultimate tensile strength $f_{\mathrm{u}}$, the strain corresponding to the ultimate tensile strength $\varepsilon_{\mathrm{u}}$ and the strain hardening parameters $n$ and $m$.

Superposition of the initial geometric imperfections in the form of buckling mode shapes was introduced in each FE model. The pattern including local imperfection with an amplitude of $d / 100$ and twist imperfection with an amplitude of $d / 50$ together with a flexural imperfection with a magnitude of $L / 1000$ was used in the parametric study. Depending on the slenderness domain, one of the cross-section imperfections was used as the leading and the other was reduced by a factor equalling 0.7 . Because the distortional instability is not a critical mode of plain channel cross-section, the distortional imperfection was presently not considered.

FB about the major principal axis is not a dominant failure mode for CFSS channel columns. 
In order to prevent the $\mathrm{FB}$ about the minor principal axis and FTB, and to force buckling to occur about the major axis, lateral restraints were introduced along the column length in the model. It is worth pointing that no such restraints were added to study minor axis FB or FTB.

GMNIA was performed to obtain the ultimate loads and failure modes using the quasi-static analysis via dynamic explicit solver in the ABAQUS software package [40].

Fig. 7 Geometry and boundary conditions of one typical FE model.

\section{Comparison with the European and Australian design resistances}

The numerical results were carefully analysed to clearly identify the failure modes. The numerical failure mode which consisted of FB about the minor principal axis or FTB was selected to evaluate the corresponding theoretical failure load. In general, the observed overall instability modes were accompanied by cross-section local buckling. Additionally, in numerous cases, the FTB mode found in the FE investigations was not pure but coupled with FB about the minor principal axis.

As already mentioned, major axis FB is not a dominant failure mode for CFSS channel columns with pin-ended supports. Therefore, this failure mode could only be obtained using appropriate boundary conditions along the column length and did not necessitate further identification.

Fig. 8, Fig. 10 and Fig. 9 present typical minor axis FB, major axis FB and FTB responses of selected FE models, respectively.

Fig. 8 FB about minor axis of FE column C100x40x6x1500 - duplex grade.

Fig. 9 FB about major axis of FE column C80x40x4x2000 - ferritic grade.

Fig. 10 FTB of FE column C160x90x4x2500 - austenitic grade.

The generated numerical data were used to assess the appropriateness of the currently available design methods i.e. according to Eurocode 3 EN 1993-1-4 [33], EN 1993-1-1 [34], and the 
Australian code AS/NZS 4673:2001 [35]. For the design according to EN 1993-1-4 [33], two values of the imperfection factor $\alpha=0.49$ (buckling curve $c$ ) and $\alpha=0.76$ (buckling curve $d$ ) in conjunction with a limiting non-dimensional slenderness $\bar{\lambda}_{0}=0.2$ were considered to predict FB loads about the minor and major principal axes, respectively. The buckling curve $b(\alpha=$ 0.34 and $\bar{\lambda}_{0}=0.2$ ) was used to predict FTB loads. Note that the change of imperfection factor in the calculation of the column FB resistances affects the calculation of the FTB resistances.

The effective areas of Class 4 cross-sections were obtained following the procedure described in Clause 4.4 of EN 1993-1-5 [16] considering the reduction factors provided in [33]. According to AS/NZS 4673:2001 [35], the minor axis column buckling strengths were calculated using the explicit approach that accounts for material nonlinearities by introducing the parameters $\alpha$, $\beta, \lambda_{0}$ and $\lambda_{1}$ (as provided in Table 1). To evaluate the influence of the shift of the centroid when considering the effective cross-section, the data points related to slender cross-sections (Class 4) were selected and reassessed based on the EN1993-1-4 interaction formulae. The direction of the predicted shift in plain channel section leads to a secondary minor axis bending moment $M_{\mathrm{z}, \mathrm{pred}}=N_{\mathrm{u}, \text { pred }} \cdot e_{\mathrm{Nz}}$ with no secondary major axis bending moment. A shift of the effective centroid towards the web causes bending towards the web.

For reason of clarity, graphical comparisons between the predicted design resistances i.e. the buckling curves $c$ and $d$, in conjunction with a limiting non-dimensional slenderness $\bar{\lambda}_{0}=0.2$, and the normalised FE compressive resistances for CFSS channel columns, including both nonslender and slender sections, are provided in Fig. 11 for FB about the minor principal axis and in Fig. 12 for FB about the major principal axis. In these two graphs, a different label was selected for each family of stainless steel. To be complete, the EN 1993-1-4 [33] buckling curve for cold-formed open sections, employing the imperfection factor $\alpha=0.49$ and limiting slenderness $\bar{\lambda}_{0}=0.4$ is also depicted in Fig. 11 and Fig. 12. Additionally, Fig. 13 compares the normalised FE compressive resistances related to FB about minor principal axis to the AS/NZS 
buckling curves based on the explicit approach (AS/NZS 4673:2001 [35]), which is applicable to cold-formed sections only, for each of the stainless steel grades. Experimental data for channel section resistances from [22] and [12] were also added in Fig. 11, Fig. 12 and Fig. 13.

The FE ultimate loads are normalised by the squash load for each stainless steel family and are plotted against the non-dimensional column slenderness ratio. The normalised FE results are based on the enhanced average yield strength of the cross-section [41], i.e. including the corner strength enhancement.

Fig. 11 Comparison between normalised FE results and EN 1993-1-4 curves for FB about minor axis.

Fig. 12 Comparison between normalised FE results and EN 1993-1-4 for FB about major axis.

Fig. 13 Comparison between normalised FE results and AS/NZS 4673 curves for FB about minor axis. In Fig. 13, for slenderness values lower than the plateau length, it was decided to use the formulation proposed in [47] where strain-hardening effects are accounted for. Therefore, instead of using the classical horizontal yield limit proposed in conventional approaches, a compression level equal to $f_{\mathrm{u}}$ (the tensile strength) is assumed to be attained as the slenderness approaches zero. Thus, the maximum reduction factor $\chi$ equals $f_{\mathrm{u}} / f_{\mathrm{y}}$, which improves the comparison between the design and numerical strengths.

The points, representing pairs of corresponding FE data $\left(N_{\mathrm{b}, \mathrm{u}, \mathrm{FEM}}\right)$ and design data $\left(N_{\mathrm{b}, \mathrm{u}, \mathrm{pred}}\right)$, relate to minor axis FB (firstly compared to EN 1993-1-4 then to AS/NZS 4673 design predictions), FB about major axis and FTB are plotted in Fig. 14, including both slender and non-slender cross-sections and all analysed stainless steel grades. 
(a) FE data versus design data EN 1993-1-4 (buckling curve $\alpha=0.49 \bar{\lambda}_{0}=0.2$ ) / FB minor axis

(c) FE data versus design data EN 1993-1-4 (buckling curve $\alpha=0.34 \bar{\lambda}_{0}=0.2$ ) / FTB (b) FE data versus design data AS/NZS 4673 / FB minor axis

(d) FE data versus design data EN 1993-1-4 (buckling curve $\alpha=0.49 \bar{\lambda}_{0}=0.2$ ) / FB major axis

Fig. 14 Comparison of FE resistance with design resistance predictions for both slender and nonslender cross-sections.

In order to provide an indication of how the design procedures predict the strength, Table 7 provides the numerical-to-predicted ratios per grade and per cross-section Class.

Following to the results of the comparative analysis, the following conclusions can be drawn:

(1) The buckling curve provided in EN 1993-1-4 [33] with $\alpha=0.49$ and $\bar{\lambda}_{0}=0.4$ (see Fig. 11 and Fig. 12) leads to a significant number of unsafe predictions for CFSS channel columns considering FB about either the minor or the major principal axis. Hence, we shall emphasize the necessity for a lower buckling curve or a partial safety factor greater than the current value of $\gamma_{\mathrm{M} 1}=1.10$.

(2) For minor axis FB of columns made of austenitic grades, the limiting non-dimensional slenderness appears to be closer to 0.2 while this does not seem to be the case for duplex and ferritic grades. At low slenderness, i.e. in the plateau region with $\bar{\lambda}_{z}<0.2$, a number of experimental data, especially from [12], [22] exceed the squash load. This is due to the beneficial influence of strain hardening caused by cold working on the cross-section capacity.

(3) The comparison between the FE data for minor axis FB and the codified ones based on buckling curves $c$ and $d$ in conjunction with a limiting slenderness of 0.2 reveals considerably unsafe predictions too in the low and, partially, in the intermediate slenderness range when $\bar{\lambda}_{z}$ $\approx 0.2-1.0$. The same can be concluded for major axis buckling however in a minor extent. This is quite clear in Fig. 11 especially for austenitic grades. In these cases, a cross-section instability followed by shifting of the neutral axis in conjunction with a curved stress-strain curve prior 
the yield strength result in significant flexural strength degradation.

In the intermediate slenderness range, the varying nonlinear stress-strain material law leads to different compressive capacity for columns made of different stainless steel grades. At high slenderness however, when the column behaviour is governed by elastic FB, the difference is not significant. In this slenderness range, the FE data are well represented by the codified curves, especially for non-slender sections.

(4) The predictive curve $c$ is in good agreement with FE data for duplex and ferritic grade considering non-slender channel sections. However, buckling curve $d$ seems more appropriate for austenitic grades (see Table 7). When the EN 1993-1-4 interaction formula (eq. (12)) is used in conjunction with the suitable buckling curve, safe but conservative results with higher scatter are obtained for all stainless steel families. Again, the buckling curve $c$ provides acceptable agreement for the duplex and ferritic families with slender sections while the buckling curve $d$ offers safer design predictions for the austenitic family.

(5) It can also be deduced from Fig. 12 and Fig. 14d that buckling curve $c$ (and $d$ ) in conjunction with a limiting slenderness of 0.2 may be suitable to predict major axis FB for non-slender cross-sections made of duplex and ferritic stainless steel grades (and austenitic grade). Note that the same can be stated for slender cross-sections when they are used in conjunction with the interaction formula for major axis flexural buckling and secondary minor axis bending moment.

(6) The explicit approach of AS/NZS 4673:2001 [35] provides considerably precise and reliable predictions of the strength of non-slender CFSS plain channel columns for minor axis FB (see Table 7) with a lower scatter compared to the Eurocode predictions. In addition, similar conclusion can be drawn when Eq. (28) is used for slender cross-section, when secondary minor axis bending moment should be considered.

(7) The scatter of the data is significantly higher for the FTB mode, also when interaction 
between the axial force and the secondary minor axis bending moment is considered. A higher level of conservativeness of the codified predictions is also obtained.

\section{Reliability assessment}

\subsection{Safety factor $\gamma_{M 1}$}

In order to evaluate the level of reliability of the European and Australian codified buckling curves for stainless steel plain channel section columns, which were found to be rather unsatisfactory for FB about the minor or major principal axis or for FTB, the values of the partial factors for member resistance $\gamma_{\mathrm{M} 1}$ [33], [34], and of the resistance factors $\phi_{\mathrm{c}}$ [35], are calculated based on a statistical analysis. The provisions given in Annex D of EN 1990 [48] and the methodology described in [49] are presently employed. However, Eq. (30) was used to obtain the parameter $d$, instead of the equation provided in [49].

$$
d=\frac{\ln \left(\frac{N_{\mathrm{b}, \mathrm{Rd}, 2}}{N_{\mathrm{b}, \mathrm{Rd}, 1}}\right)}{\ln \left(\frac{A_{2}}{A_{1}}\right)}
$$

The design buckling resistances $N_{\mathrm{b}, \mathrm{Rd}, 1}$ and $N_{\mathrm{b}, \mathrm{Rd}, 2}$ in Eq. (30) are calculated taking into account a slight increase of the gross cross-sectional area $A$. Additionally, the parameter $V_{\mathrm{rt}}$ is adopted in accordance with Equation D.16b of EN1990:2002 Annex D [48], instead of Eq. (23) of [49]. As for the coefficients of variation, the ones proposed in [49] for $f_{y}$, which are based on thorough statistical evaluation, were used. They equal $0.06,0.045$ and 0.03 for austenitic, ferritic and duplex grades respectively. The coefficient of variation for the geometric properties is considered equal to 0.05 , which is the value employed in the development of the AISC stainless steel design guide [50]. In the analyses, the material over-strength factors were taken as 1.3 for the austenitic, 1.1 for the duplex and 1.2 for the ferritic grade.

The numerical data from the parametric study performed in Section 7 were used in the present 
statistical analyses. In compliance with EN 1990, Annex D, Clause D8.2.2.5 [48], the total population of the test was divided into sub-sets, depending on the group of data being considered, respectively for minor or major axis FB or FTB and their interaction with uniaxial minor axis moment, cross-section slenderness (non-slender Class 3 and slender Class 4) and stainless steel family. In this case, the methodology allows to use the total number of data points in the original series to assess the fractile factor which avoids large safety factors due to a smaller number of data points in each sub-set. Herein, it is worth pointing that the number of data points in each sub-set eventually remained high.

A summary of the key results of the reliability analysis is presented in Table 8 . The parameters of interest useful for a better understanding of the results are as follows: $n$ which is the total number of data points; $b$ which is the average ratio of experimental (here FE)-to-model resistance, which is based on the least squares fit of the slope of the $r_{e i}$ versus $\mathrm{r}_{t i}$ plot for each set of data, see Eq. (31); the coefficient of variation $V_{\delta}$ which is a measure of the variability of the FE-to-model resistance; and $\gamma_{\mathrm{M} 1}$ is the partial safety factor for the buckling resistance.

$b=\sum_{i=1}^{n} \frac{r_{\mathrm{ei}} r_{\mathrm{ti}}}{r_{\mathrm{ti}}^{2}}$

Based on the results of the reliability analysis, the following comments can be drawn:

(1) For FB about both principal axes and for non-slender sections, the assessment confirms that the Eurocode buckling curve $c\left(\alpha=0.49, \bar{\lambda}_{0}=0.2\right)$ provides reliable predictions for both the duplex and ferritic grades and that, conversely, for the austenitic grade, the buckling curve $d$ seems more appropriate.

(2) The CFSS duplex and ferritic channel columns subject to interaction of minor/major axis FB and minor axis bending should also be calculated using the buckling curve $c$, see Table 8 . It should be emphasized that this does not comply to the proposal of the Design Manual for Structural Stainless Steel [6], where the more conservative buckling curve $d$ is adopted. 
However, for austenitic grades, a difference should be made between interaction between minor axis buckling or major axis buckling with the secondary bending moment. In the first case (minor axis FB and minor axis bending), both curves $c$ and $d$ provide unsatisfactory results. In the second (major axis FB and minor axis bending), the buckling curve $d$ appears to be adequate.

(3) For minor axis FB (non-slender channel sections), the reliability study shows that the partial safety factors for the current AS/NZS 4673 explicit approach are $0.84,1.07$ and 0.96 for the austenitic, duplex and ferritic stainless steel grades respectively. In addition, the Australian codified procedure covering interaction of axial compression and uniaxial minor axis moment (for slender cross-sections) provides reliable results with the partial safety factors equal to 0.83 , 1.07 and 0.99 for austenitic, duplex and ferritic stainless steel grades respectively; meaning that this approach seems more suitable for channel column design in comparison with the traditional Eurocode approach.

(4) For the FTB mode, the theoretical predictions are rather unsatisfactory leading to safety factors ranging between 0.98 and 1.17. However, it should be noted that the buckling curve $b$ leads to safe while rather conservative design predictions.

\subsection{Resistance factor $\phi_{\mathrm{c}}$}

The appropriate resistance factor $\phi_{c}$ to be used in conjunction with the rules of AS/NZS 4673 has been calculated on the basis of the statistics shown in Table 7, and the LRFD (Load and Resistance Factor Design) framework, see Section K2.1.1 of the North American Specification [51]. The resistance factor, taking into account the dead and live load combination, is obtained from the Eq. (32) below:

$\phi_{\mathrm{c}}=C_{\phi}\left(M_{\mathrm{m}} F_{\mathrm{m}} P_{\mathrm{m}}\right) e^{-\beta_{\mathrm{o}} \sqrt{V_{\mathrm{M}}^{2}+V_{\mathrm{F}}^{2}+C_{\mathrm{P}} V_{\mathrm{P}}^{2}+V_{\mathrm{Q}}^{2}}}$

where $C_{\phi}=1.52$ is the calibration coefficient; $M_{\mathrm{m}}=1.1$ and $F_{\mathrm{m}}=1.0$ are the mean values of the Material $(M)$ and Fabrication $(F)$ factors for concentrically loaded compression members, 
respectively; $V_{\mathrm{M}}=0.1$ and $V_{\mathrm{F}}=0.05$ are the coefficients of variation of the aforementioned factors; $\beta_{0}$ is the target reliability index for LRFD, which amounts to 2.5 for structural members; $P_{\mathrm{m}}$ and $V_{\mathrm{P}}$ are the mean value and the coefficient of variation of the Professional factor $(P)$, expressed as the test-to-design strength ratio; $V_{\mathrm{Q}}$ is the coefficient of variation of load effect, which is equal to 0.21 for LRFD, and $C_{\mathrm{P}}$ is the correction factor calculated in the following manner:

$$
\begin{array}{ll}
C_{\mathrm{P}}=\left(1+\frac{1}{n}\right) \frac{m}{m-2} & \text { for } n \geq 4 \\
C_{\mathrm{P}}=5.7 & \text { for } n=3
\end{array}
$$

where $m=n-1$ represents the degrees of freedom and $n$ represents the number of tests.

In Table 9, the resistance factors $\phi_{\mathrm{c}}$ for CFSS channels are presented both for pure compression (non-slender sections) and when interaction between compression and minor axis bending moment should be considered. Considering all of the available numerical data, the resistance factor $\phi_{c}$ is always greater than 0.9 , which is the value for column design as per AS/NZS 4673 [35]. This is firstly due to the particular shape of the buckling curve, which is able to follow the behaviour in the low and intermedium slenderness range quite well, combined with, the scaling of the curve depending on the stainless steel family.

\section{Conclusion}

In the present paper, a comprehensive FE assessment of the structural behaviour of cold-formed stainless steel plain channel columns under pure compression was carried out. Minor and major axis buckling as well as flexural-torsional buckling are carefully addressed. The derived FE model is then used to perform a parametric study in which austenitic, duplex and ferritic grades are studied over the whole column slenderness range, for non-slender and slender (Class 4) cross-sections. The generated data are then compared to the current European EN1993-1-4 [33] and Australian design methods AS/NZS 4673 [35]. The appropriateness of the different 
codified buckling curves (considering the shift of the centroid for Class 4 cross-sections) is assessed through reliability analyses according to the methodologies proposed in EN1990:2002 Annex D [48] and in the North American Specification [51].

The following conclusions were drawn:

- The parameters $\alpha$ and $\bar{\lambda}_{0}$ which are respectively equal to 0.49 and 0.4 in the existing EN1993-1-4 should be revised for the design of cold-formed stainless steel plain channel columns.

- For minor axis flexural buckling of plain channel section columns, the buckling curve $c$ in conjunction with the non-dimensional limiting slenderness $\bar{\lambda}_{0}=0.2$ may be used for ferritic and duplex grades for all cross-section classes. Whereas, the buckling curve $d$ together with $\bar{\lambda}_{0}=0.2$ is more suitable for cold-formed austenitic channel columns with nonetheless the exception of slender cross-sections (i.e. when minor axis FB interacts with minor axis moment).

- The buckling curve $c$ in conjunction with the non-dimensional limiting slenderness $\bar{\lambda}_{0}$ $=0.2$ appears to be more appropriate to predict major-axis flexural buckling of coldformed channel columns for duplex and ferritic grades, while the buckling curve $d$ may be proposed for the austenitic grade again.

- The use of buckling curve $b$ in conjunction with $\bar{\lambda}_{0}=0.2$ to predict the flexural-torsional buckling leads to safe but quite conservative results characterized by significantly higher scatter.

- Very good agreement was found when the AS/NZS 4673 explicit approach is used. It is therefore proposed that the factor $\eta=\alpha\left(\bar{\lambda}-\bar{\lambda}_{0}\right)$ in Equation (5.7), Clause 5.4.2 of EN 1993-1-4, shall be replaced by Equation (23) with the values of $\alpha, \beta, \bar{\lambda}_{0}$ and $\bar{\lambda}_{1}$ as in Table 1. In this case, the safety factors $\gamma_{\mathrm{M} 1}$ as per EN1990:2002 Annex D, would be 
lower than 1.10 for all stainless steel alloys and all cross-section classes.

\section{Acknowledgements}

This investigation is supported by the Serbian Ministry of Education, Science and Technological Development through the TR-36048 project. 


\section{References}

[1] F. Yiu, T. Peköz, Design of cold-formed steel plain channels, Committee on Specifications for the Design of Cold-Formed Steel Structural Members, American Iron and Steel Institute, 2006

[2] S.P. Timoshenko, J.M. Gere, Theory of elastic stability, 2nd edition, McGraw-Hill, New York, 1961.

[3] K. J. R. Rasmussen, G. J. Hancock, Design of Thin-Walled Plain Channel Section Columns Against Flexural Buckling, Thin-Walled Structures. 20 (1994) 219-240.

[4] B. Young, K.J.R. Rasmussen, Tests of Fixed-Ended Plain Channel Columns, Journal of Structural Engineering. 124 (1998) 131-139.

[5] B. Young, K.J.R. Rasmussen, Behaviour of cold-formed singly symmetric columns, Thin-Walled Structures. 33 (1999) 83-102.

[6] Afshan S., Arrayago I., Baddoo N., Gardner L., Gedge G., Jandera M., Real E., Rossi B., Stranghöner N., Zhao O. (2017). Design manual for structural stainless steel. Berkshire: The Steel Construction Institute.

[7] L. Gardner, The use of stainless steel in structures, Prog. Struct. Eng. Mater. 7 (2) (2005) 45-55.

[8] L. Gardner, Aesthetics, economics and design of stainless steel structures, Advanced Steel Construction. 4 (2) (2008) 113-122.

[9] N.R. Baddoo, Stainless steel in construction: A review of research, applications, challenges and opportunities, J. Construct. Steel Res. 64 (2008) 1199-1206.

[10] K.J.R. Rasmussen, Full-range stress-strain curves for stainless steel alloys, J. Construct. Steel Res. 59 (2003) 47-61.

[11] I. Arrayago, E. Real, L. Gardner, Description of stress-strain curves for stainless steel alloys, Materials and Design. 87 (2015) 540-552.

[12] J. Dobrić, D. Budjevac, Z. Marković, N. Gluhović, Behaviour of stainless steel press-braked channel sections under compression, J. Construct. Steel Res. 139 (2017) 236-253.

[13] G.P. Mulligan, T. Peköz, Local Buckling Interaction in Cold-Formed Columns, Journal of Structural Engineering. 113 (1987) 604-620.

[14] J. Ye, I. Hajirasouliha, J. Becque, Experimental investigation of local-flexural interactive buckling of cold-formed steel channel columns, Thin-Walled Structures. 125 (2018) 245-258.

[15] Eurocode 3: Design of Steel Structures - Part 1-3: General rules - Supplementary rules for coldformed members and sheeting EN 1993-1-3, Brussels, Belgium, 2006.

[16] Eurocode 3: Design of steel structures - Part 1-5: Plated structural elements EN 1993-1-5, Brussels, Belgium, CEN 2006.

[17] A. Moldovan, Compression Tests on Cold-Formed Steel Columns with Monosymmetrical Section, Thin-Walled Structures. 20 (1994) 241-252.

[18] J. Becque, K.J.R. Rasmussen, Experimental Investigation of the Interaction of Local and Overall Buckling of Stainless Steel I-Columns, Journal of Structural Engineering. 135 (2009) 1340-1348.

[19] B. Rossi, J.-P. Jaspart, K. J. Rasmussen, Combined distortional and overall flexural-torsional buckling of cold-formed stainless steel sections: Experimental investigations, Journal of Structural Engineering. 136 (4) (2010) 354-360.

[20] M. Lecce and K. J. Rasmussen. Experimental Investigation of the Distortional Buckling of ColdFormed Stainless Steel Sections. Research Report No R844, The University of Sydney, 2004.

[21] M. Lecce, K. J. Rasmussen, Distortional Buckling of Cold-Formed Stainless Steel Sections: Experimental Investigation, Journal of Structural Engineering 132 (4) (2006) 497-504.

[22] H. Kuwamura, Local Buckling of Thin-Walled Stainless Steel Members, Steel Structures. 3 (2003) 191-201.

[23] K. Roy, J.B.P. Lim, Numerical investigation into the buckling behaviour of face-to-face built-up cold-formed stainless steel channel sections under axial compression, Structures. 20 (2019) 42-73.

[24] J. Becque, M. Lecce, K.J.R Rasmussen, The direct strength method for stainless steel compression members, Journal of constructional steel research. 64 (2009) 1231-1238.

[25] J. Dobrić, Z. Marković, D. Budjevac, M. Spremić, N. Fric, Resistance of the cold-formed built-up stainless steel members - Part I: Experiment, J. Construct. Steel Res. 145 (2018) 552-572.

[26] J. Ye, S.M. Mojtabaei, I. Hajirasouliha, P. Shepherd, K. Pilakoutas, Strength and deflection behaviour of cold-formed steel back-to-back channels, Engineering Structures. 177 (2018) 641654.

[27] M. Theofanous, A. Liew, L. Gardner, Experimental study of stainless steel angles and channels in bending, Structures. 4 (2015) 80-90.

[28] Y. Liang, O. Zhao, Y. Long, L. Gardner, Stainless steel channel sections under combined compression and minor axis bending - Part 1: Experimental study and numerical modelling, Journal of Constructional Steel Research. 152 (2019) 154-161.

[29] Y. Liang, O. Zhao, Y. Long, L. Gardner, Stainless steel channel sections under combined compression and minor axis bending - Part 2: Parametric studies and design, Journal of Constructional Steel Research. 152 (2019) 162-172

[30] Ç. Dizdar, E. Baran, C. Topkaya, Strength and stiffness of floor trusses fabricated from cold- 
formed steel lipped channels, Engineering Structures. 181 (2019) 437-457.

[31] J. Zhao, K. Sun, C. Yu, J. Wang, Test and direct strength design on cold-formed steel channel beams with web holes, Engineering Structures. 184 (2019) 434-446.

[32] A.M. Yousefi, J.B.P. Lim, G.C. Clifton, Web crippling strength of perforated cold-formed ferritic stainless steel unlipped channels with restrained flanges under one-flange loadings, Thin-Walled Structures. 137 (2019) 94-105.

[33] Eurocode 3: Design of steel structures - part 1-4: General rules - supplementary rules for stainless steels, including amendment A1 (2015), EN 1993-1-4:2006+A1:2015, Brussels, Belgium, CEN 2015.

[34] Eurocode 3: Design of steel structures - Part 1-1: General rules and rules for buildings EN 19931-1, Brussels, Belgium, CEN 2005.

[35] AS/NZS 4673:2001 - Cold-formed stainless steel structures. Australian - New Zealand Standard. Standards Australia, 2001.

[36] SEI/ASCE 8-02: Specification for the Design of Cold-Formed Stainless Steel Structural Members, American Society of Civil Engineers, 2003.

[37] K.J.R. Rasmussen, J. Rondal, Column curves for stainless steel alloys, Journal of constructional steel research, 54 (2000) 89-107.

[38] K. J. R. Rasmussen, J. Rondal, Explicit Approach to Design of Stainless Steel Columns, ASCE Journal of structural engineering, 123(7) (1997) 857-863.

[39] J. Dobrić, B. Rossi, Column curves for stainless steel lipped channel sections, Journal of Structural Engineering, accepted for publication.

[40] ABAQUS User Manual. Version 6.12. Providence, RI, USA: DS SIMULIA Corp; 2012.

[41] B. Rossi, S. Afshan, L. Gardner, Strength enhancements in cold-formed structural sections - Part II: Predictive models, Journal of Constructional Steel Research, 83 (2013) 189-196.

[42] K.J.R. Rasmussen, G.J. Hancock, Design of cold-formed stainless steel tubular members I: Columns, J. Struct. Eng. ASCE 119 (8) (1993) 2349-2367.

[43] L. Gardner, D. A. Nethercot, Numerical modeling of stainless steel structural components a consistent approach, J. Struct. Eng., ASCE 130 (10) (2004) 1586-1601.

[44] B.W. Schafer, T. Pekoz, Computational modeling of cold-formed steel: characterizing geometric imperfections and residual stresses, J. Construct. Steel Res. 47 (1998) 193-210.

[45] Execution of steel structures and aluminium structures - Part 2: Technical requirements for steel structures EN 1090-2, Brussels, Belgium, CEN 2008.

[46] N. Saliba, L. Gardner, Experimental study of the shear response of lean duplex stainless steel plate girders, Eng. Struct. 46 (2013) 375-391.

[47] B. Rossi, K.J.R. Rasmussen, Carrying Capacity of Stainless Steel Columns in the Low Slenderness Range, Journal of Structural Engineering, 139(6) (2013), 1088-1092.

[48] Eurocode: Basis of structural design EN 1990, Brussels, Belgium, European Committee for Standardization (CEN); 2002.

[49] S. Afshan, P. Francis, N. R. Baddoo, L. Gardner, Reliability analysis of structural stainless steel design provisions, J. Construct. Steel Res., 114 (2015) 293-304.

[50] AISC, Design Guide 27: Structural Stainless Steel, American Institute of Steel Construction, 2013

[51] AISI-S100-16 (2016), North American Specification for the Design of Cold-Formed Steel Structural Members, AISI Standard, American iron and Steel Institute. 
Table 1. Values of $\alpha, \beta, \lambda_{0}$ and $\lambda_{1}$ depending on stainless steel grade, in AS/NZS 4673 [35].

\begin{tabular}{llll}
\hline Parameters & \multicolumn{3}{l}{ Stainless steel grades } \\
\cline { 2 - 4 } & Austenitic & Ferritic & Duplex \\
& \multicolumn{3}{c}{ EN1.4003 } \\
\hline$\alpha$ & 1,59 & 0,94 & 1,16 \\
$\beta$ & 0,28 & 0,15 & 0,13 \\
$\lambda_{0}$ & 0,55 & 0,56 & 0,65 \\
$\lambda_{1}$ & 0,20 & 0,27 & 0,42 \\
\hline
\end{tabular}

Table 2. Ultimate buckling load - Experimental [19] and FEM results.

\begin{tabular}{lcccccc} 
Lengths of specimens & \multicolumn{3}{c}{ Repeated tests } & Experiments & FEM & Ratio \\
\cline { 2 - 7 } & 1 & 2 & 3 & $N_{\text {b,u,exp,mean }}$ & $N_{\text {b,u,FM }}$ & $N_{\text {b,u,FEM }} / N_{\text {b, , exp,mean }}$ \\
\hline 400 & 80.9 & 80.3 & 80.6 & 80.6 & 80.0 & 0.99 \\
700 & 80.7 & 81.1 & 78.8 & 80.2 & 80.4 & 1.00 \\
900 & 80.8 & 80.1 & 76.9 & 79.3 & 80.1 & 1.01 \\
1200 & 78.0 & 78.5 & 77.4 & 78.0 & 77.8 & 1.00 \\
1400 & 76.4 & 76.9 & 75.5 & 76.3 & 76.8 & 1.01 \\
1800 & 72.7 & 70.7 & 72.3 & 71.9 & 72.3 & 1.01 \\
2200 & 67.5 & 69.6 & 69.0 & 68.7 & 68.6 & 1.00 \\
2600 & 65.1 & 61.9 & 59.7 & 62.2 & 62.0 & 1.00 \\
3000 & 49.0 & 49.0 & 48.9 & 49.0 & 50.4 & 1.03 \\
3200 & 42.8 & 49.6 & 49.0 & 47.1 & 48.3 & 1.02 \\
\hline Mean & & & & & & 1.01 \\
CoV (\%) & & & & & & 1.81 \\
\hline
\end{tabular}

Table 3. Ultimate buckling load - Experimental [21] and FEM results.

\begin{tabular}{lccc} 
FE models / Specimens & Experiments & FEM & Ratio \\
\cline { 2 - 4 } Designations as in [21] & $N_{\mathrm{b}, \mathrm{u}, \exp }$ & $N_{\mathrm{b}, \mathrm{u}, \mathrm{FEM}}$ & $N_{\mathrm{b}, \mathrm{u}, \mathrm{FEM}} / N_{\mathrm{b}, \mathrm{u}, \mathrm{exp}}$ \\
\hline 304D1a / 304D1b & 101.5 & 100.8 & 0.99 \\
304D2a / 304D2b & 104.0 & 103.7 & 1.00 \\
304DS1a & 132.0 & 132.8 & 1.01 \\
304Ds1b & 134.0 & 135.7 & 1.01 \\
\hline Mean & & & 1.00 \\
CoV (\%) & & & 0.95
\end{tabular}


Table 4. Channel - Cross-section geometries and lengths included in the present study.

\begin{tabular}{|c|c|c|c|c|c|}
\hline Section & $\begin{array}{c}\text { Column length } L \\
(\mathrm{~mm})\end{array}$ & $\begin{array}{c}\text { Web depth } d \\
(\mathrm{~mm})\end{array}$ & $\begin{array}{l}\text { Flange width } b \\
(\mathrm{~mm})\end{array}$ & $\begin{array}{c}\text { Thickness } t \\
(\mathrm{~mm})\end{array}$ & $\begin{array}{c}\text { Internal radius } r_{\mathrm{i}} \\
(\mathrm{mm})\end{array}$ \\
\hline Channel 100x40x2 & $300-1800$ & 100,0 & 40,0 & 2,0 & 4,0 \\
\hline Channel 100x40x4 & $300-1800$ & 100,0 & 40,0 & 4,0 & 8,0 \\
\hline Channel 100x40x6 & $300-1800$ & 100,0 & 40,0 & 6,0 & 12,0 \\
\hline Channel 150x80x4 & $300-3000$ & 150,0 & 80,0 & 4,0 & 8,0 \\
\hline Channel 200x80x4 & $300-3000$ & 200,0 & 80,0 & 4,0 & 8,0 \\
\hline Channel 200x80x6 & $1000-1400$ & 200,0 & 80,0 & 4,0 & 12,0 \\
\hline Channel 140x60x4 & $300-3200$ & 140,0 & 60,0 & 4,0 & 8,0 \\
\hline Channel 140x60x2 & $300-2800$ & 140,0 & 60,0 & 2,0 & 4,0 \\
\hline Channel 160x90x4 & $480-3100$ & 160,0 & 90,0 & 4,0 & 8,0 \\
\hline Channel 200x100x4 & $400-3000$ & 200,0 & 100,0 & 4,0 & 8,0 \\
\hline Channel 200x100x2 & $400-2500$ & 200,0 & 100,0 & 2,0 & 4,0 \\
\hline Channel 80x40x5 & $500-1100$ & 80,0 & 40,0 & 5,0 & 10,0 \\
\hline Channel $80 \times 40 \times 4$ & $240-2300$ & 80,0 & 40,0 & 4,0 & 8,0 \\
\hline Channel 80x40x2 & $240-2300$ & 80,0 & 40,0 & 2,0 & 4,0 \\
\hline
\end{tabular}

Table 5. Key material properties of flat cross-section parts adopted in the FE models.

\begin{tabular}{lccccc}
\hline Stainless steel grade / Source & $f_{\mathrm{y}}\left(\mathrm{N} / \mathrm{mm}^{2}\right)$ & $f_{\mathrm{u}}\left(\mathrm{N} / \mathrm{mm}^{2}\right)$ & $\varepsilon_{\mathrm{u}}(\%)$ & \multicolumn{3}{c}{ Strain hardening parameters } \\
\hline EN 1.4003 / [19] & & & & $n$ & $m$ \\
EN 1.4162 / [46] & 337 & 614 & 29 & 13.5 & 2.0 \\
EN 1.4301 / [21] & 569 & 753 & 25 & 12.0 & 3.0 \\
EN 1.4301 / [12] & 251 & 703 & 57 & 5.0 & 2.2 \\
\hline
\end{tabular}

Table 6. Key material properties of corner cross-section parts adopted in the FE models.

$\overline{\text { Stainless steel grade / Source } f_{\mathrm{y}}\left(\mathrm{N} / \mathrm{mm}^{2}\right) f_{\mathrm{u}}\left(\mathrm{N} / \mathrm{mm}^{2}\right) \varepsilon_{\mathrm{u}}(\%) \text { Strain hardening parameters }}$

\begin{tabular}{llllcl} 
& & & & $n$ & $m$ \\
\hline EN 1.4003 / [19] & 525 & 624 & 10 & 13.5 & 3.4 \\
EN 1.4162 / [46] & 712 & 813 & 14 & 12.0 & 3.4 \\
EN 1.4301 / [21] & 570 & 784 & 16 & 5.0 & 3.0 \\
EN 1.4301 / [12] & 458 & 680 & 37 & 4.9 & 2.5 \\
\hline
\end{tabular}


Table 7. Design-to-numerical ratios (an average value lower than 1.0 shall indicate safe predictions).

\begin{tabular}{|c|c|c|c|c|c|}
\hline \multirow[t]{2}{*}{ Grade } & & \multirow[t]{2}{*}{ Code } & \multirow{2}{*}{$\begin{array}{c}\text { \# data } \\
\bar{\lambda}_{0}>0.2\end{array}$} & \multicolumn{2}{|c|}{$N_{\mathrm{b}, \mathrm{u}, \mathrm{FEM}} / N_{\mathrm{b}, \mathrm{u}, \mathrm{pred}}$} \\
\hline & & & & Mean & $\mathrm{CoV}(\%)$ \\
\hline \multicolumn{6}{|c|}{ EN 1993-1-4 / FB minor axis } \\
\hline \multirow[t]{4}{*}{ Austenitic } & Non-slender - Class 3 & $\alpha=0.76 \bar{\lambda}_{0}=0.2$ & 51 & 0.894 & 14.2 \\
\hline & Non-slender - Class 3 & $\alpha=0.49 \bar{\lambda}_{0}=0.2$ & 51 & 1.017 & 13.8 \\
\hline & Slender - Class 4 & $\alpha=0.76 \bar{\lambda}_{0}=0.2 \&$ Eq. (12) & 60 & 0.746 & 17.9 \\
\hline & Slender - Class 4 & $\alpha=0.49 \bar{\lambda}_{0}=0.2 \&$ Eq. (12) & 60 & 0.829 & 16.2 \\
\hline \multirow[t]{2}{*}{ Duplex } & Non-slender - Class 3 & $\alpha=0.49 \bar{\lambda}_{0}=0.2$ & 12 & 0.870 & 7.6 \\
\hline & Slender - Class 4 & $\alpha=0.49 \bar{\lambda}_{0}=0.2 \&$ Eq. (12) & 45 & 0.758 & 18.1 \\
\hline \multirow[t]{3}{*}{ Ferritic } & Non-slender - Class 3 & $\alpha=0.49 \bar{\lambda}_{0}=0.2$ & 25 & 0.878 & 7.4 \\
\hline & Slender - Class 4 & $\alpha=0.49 \bar{\lambda}_{0}=0.2 \&$ Eq. (12) & 35 & 0.725 & 15.5 \\
\hline & & AS/NZS 4673 / FB minor axis & & & \\
\hline \multirow[t]{2}{*}{ Austenitic } & Non-slender - Class 3 & $\alpha_{\text {AUS }}=1.59 \lambda_{0, \mathrm{AUS}}=0.55$ & 51 & 0.784 & 11.7 \\
\hline & Slender - Class 4 & $\alpha_{\text {AUS }}=1.59 \lambda_{0, \mathrm{AUS}}=0.55 \&$ Eq. $(28)$ & 60 & 0.644 & 14.6 \\
\hline \multirow[t]{2}{*}{ Duplex } & Non-slender - Class 3 & $\alpha_{\text {AUS }}=1.16 \lambda_{0, \mathrm{AUS}}=0.65$ & 12 & 0.889 & 11.9 \\
\hline & Slender - Class 4 & $\alpha_{\text {AUS }}=1.16 \quad \lambda_{0, \mathrm{AUS}}=0.65 \&$ Eq. $(28)$ & 45 & 0.747 & 21.5 \\
\hline \multirow[t]{3}{*}{ Ferritic } & Non-slender - Class 3 & $\alpha_{\text {AUS }}=0.94 \lambda_{0, \mathrm{AUS}}=0.56$ & 25 & 0.921 & 6.5 \\
\hline & Slender - Class 4 & $\alpha_{\text {AUS }}=0.94 \lambda_{0, \text { AUS }}=0.56 \&$ Eq. $(28)$ & 35 & 0.704 & 15.4 \\
\hline & & EN 1993-1-4 / FTB & & & \\
\hline Austenitic & Slender-Class 4 & $\alpha=0.34 \bar{\lambda}_{0}=0.2 \&$ Eq. (12) & 66 & 0.771 & 21.4 \\
\hline \multirow[t]{2}{*}{ Duplex } & Non-slender- Class 3 & $\alpha=0.34 \bar{\lambda}_{0}=0.2$ & 6 & 0.658 & 38.1 \\
\hline & Slender-Class 4 & $\alpha=0.34 \bar{\lambda}_{0}=0.2 \&$ Eq. (12) & 28 & 0.708 & 21.4 \\
\hline \multirow[t]{2}{*}{ Ferritic } & Slender-Class 4 & $\alpha=0.34 \bar{\lambda}_{0}=0.2 \&$ Eq. (12) & 33 & 0.672 & 23.7 \\
\hline & & EN 1993-1-4 / Major axis FB & & & \\
\hline \multirow[t]{4}{*}{ Austenitic } & Non-slender - Class 3 & $\alpha=0.76 \bar{\lambda}_{0}=0.2$ & 32 & 0.787 & 18.6 \\
\hline & Non-slender - Class 3 & $\alpha=0.49 \bar{\lambda}_{0}=0.2$ & 32 & 1.004 & 8.6 \\
\hline & Slender - Class 4 & $\alpha=0.76 \bar{\lambda}_{0}=0.2 \&$ Eq. (12) & 27 & 0.650 & 8.9 \\
\hline & Slender - Class 4 & $\alpha=0.49 \bar{\lambda}_{0}=0.2 \&$ Eq. (12) & 27 & 0.701 & 9.7 \\
\hline \multirow[t]{2}{*}{ Duplex } & Non-slender - Class 3 & $\alpha=0.49 \bar{\lambda}_{0}=0.2$ & 6 & 0.919 & 11.6 \\
\hline & Slender - Class 4 & $\alpha=0.49 \bar{\lambda}_{0}=0.2 \&$ Eq. (12) & 19 & 0.736 & 19.2 \\
\hline \multirow[t]{2}{*}{ Ferritic } & Non-slender - Class 3 & $\alpha=0.49 \bar{\lambda}_{0}=0.2$ & 16 & 0.908 & 11.5 \\
\hline & Slender - Class 4 & $\alpha=0.49 \bar{\lambda}_{0}=0.2 \&$ Eq. (12) & 14 & 0.603 & 4.4 \\
\hline
\end{tabular}


Table 8. Results of the reliability assessment.

\begin{tabular}{|c|c|c|c|c|c|c|}
\hline \multirow[t]{2}{*}{ Grade } & & Code & $\begin{array}{l}\text { \# data } \\
\bar{\lambda}>\bar{\lambda}_{0}\end{array}$ & $b$ & $V_{\delta}$ & $\gamma_{\mathrm{M} 1}$ \\
\hline & & \multicolumn{5}{|l|}{ EN 1993-1-4 / FB minor axis } \\
\hline \multirow[t]{4}{*}{ Austenitic } & Non-slender - Class 3 & $\alpha=0.76 \bar{\lambda}_{0}=0.2$ & 51 & 1.078 & 0.101 & 0.95 \\
\hline & Non-slender - Class 3 & $\alpha=0.49 \bar{\lambda}_{0}=0.2$ & 51 & 0.976 & 0.093 & 1.03 \\
\hline & Slender - Class 4 & $\alpha=0.76 \bar{\lambda}_{0}=0.2 \&$ Eq. (12) & 60 & 1.167 & 0.130 & 1.17 \\
\hline & Slender - Class 4 & $\alpha=0.49 \bar{\lambda}_{0}=0.2 \&$ Eq. (12) & 60 & 1.057 & 0.120 & 1.24 \\
\hline \multirow[t]{2}{*}{ Duplex } & Non-slender - Class 3 & $\alpha=0.49 \bar{\lambda}_{0}=0.2$ & 12 & 1.139 & 0.027 & 0.91 \\
\hline & Slender - Class 4 & $\alpha=0.49 \bar{\lambda}_{0}=0.2 \&$ Eq. (12) & 45 & 1.235 & 0.103 & 1.10 \\
\hline \multirow[t]{3}{*}{ Ferritic } & Non-slender - Class 3 & $\alpha=0.49 \bar{\lambda}_{0}=0.2$ & 25 & 1.116 & 0.038 & 0.89 \\
\hline & Slender - Class 4 & $\alpha=0.49 \bar{\lambda}_{0}=0.2 \&$ Eq. (12) & 35 & 1.224 & 0.094 & 1.04 \\
\hline & & AS/NZS 4673 / FB minor axis & & & & \\
\hline \multirow[t]{2}{*}{ Austenitic } & Non-slender - Class 3 & $\alpha_{\mathrm{AUS}}=1.59 \lambda_{0, \mathrm{AUS}}=0.55$ & 51 & 1.322 & 0.082 & 0.84 \\
\hline & Slender - Class 4 & $\alpha_{\text {AUS }}=1.59 \lambda_{0, \mathrm{AUS}}=0.55 \&$ Eq. $(28)$ & 60 & 1.483 & 0.096 & 0.83 \\
\hline \multirow[t]{2}{*}{ Duplex } & Non-slender - Class 3 & $\alpha_{\text {AUS }}=1.16 \lambda_{0, \mathrm{AUS}}=0.65$ & 12 & 1.135 & 0.042 & 1.07 \\
\hline & Slender - Class 4 & $\alpha_{\text {AUS }}=1.16 \lambda_{0, \mathrm{AUS}}=0.65 \&$ Eq. $(28)$ & 45 & 1.315 & 0.115 & 1.07 \\
\hline \multirow[t]{3}{*}{ Ferritic } & Non-slender - Class 3 & $\alpha_{\mathrm{AUS}}=0.94 \lambda_{0, \mathrm{AUS}}=0.56$ & 25 & 1.105 & 0.034 & 0.96 \\
\hline & Slender - Class 4 & $\alpha_{\mathrm{AUS}}=0.94 \lambda_{0, \mathrm{AUS}}=0.56 \&$ Eq. $(28)$ & 35 & 1.263 & 0.091 & 0.99 \\
\hline & & EN 1993-1-4 / FTB & & & & \\
\hline Austenitic & Slender - Class 4 & $\alpha=0.34 \bar{\lambda}_{0}=0.2 \&$ Eq. (12) & 66 & 1.266 & 0.161 & 1.17 \\
\hline \multirow[t]{2}{*}{ Duplex } & Non-slender - Class 3 & $\alpha=0.34 \bar{\lambda}_{0}=0.2$ & 6 & 1.465 & 0.075 & 1.07 \\
\hline & Slender - Class 4 & $\alpha=0.34 \bar{\lambda}_{0}=0.2 \&$ Eq. (12) & 28 & 1.333 & 0.111 & 1.03 \\
\hline \multirow[t]{2}{*}{ Ferritic } & Slender - Class 4 & $\alpha=0.34 \bar{\lambda}_{0}=0.2 \&$ Eq. (12) & 33 & 1.415 & 0.128 & 0.98 \\
\hline & & EN 1993-1-4 / Major axis FB & & & & \\
\hline \multirow[t]{4}{*}{ Austenitic } & Non-slender - Class 3 & $\alpha=0.76 \bar{\lambda}_{0}=0.2$ & 32 & 1.053 & 0.056 & 1.00 \\
\hline & Non-slender - Class 3 & $\alpha=0.49 \bar{\lambda}_{0}=0.2$ & 32 & 0.965 & 0.050 & 1.07 \\
\hline & Slender - Class 4 & $\alpha=0.76 \bar{\lambda}_{0}=0.2 \&$ Eq. (12) & 27 & 1.596 & 0.045 & 0.65 \\
\hline & Slender - Class 4 & $\alpha=0.49 \bar{\lambda}_{0}=0.2 \&$ Eq. (12) & 27 & 1.519 & 0.052 & 0.69 \\
\hline \multirow[t]{2}{*}{ Duplex } & Non-slender - Class 3 & $\alpha=0.49 \bar{\lambda}_{0}=0.2$ & 6 & 1.024 & 0.029 & 1.10 \\
\hline & Slender - Class 4 & $\alpha=0.49 \bar{\lambda}_{0}=0.2 \&$ Eq. (12) & 19 & 1.235 & 0.086 & 1.04 \\
\hline \multirow[t]{2}{*}{ Ferritic } & Non-slender - Class 3 & $\alpha=0.49 \bar{\lambda}_{0}=0.2$ & 16 & 1.033 & 0.048 & 1.04 \\
\hline & Slender - Class 4 & $\alpha=0.49 \bar{\lambda}_{0}=0.2 \&$ Eq. (12) & 14 & 1.739 & 0.021 & 0.58 \\
\hline
\end{tabular}

Table 9. Results of the reliability assessment for AS/NZS 4673:2001.

\begin{tabular}{lcccc}
\hline Dataset & $P_{\mathrm{m}}$ & $V_{\mathrm{P}}$ & $n$ & $\phi_{\mathrm{c}}$ \\
\hline Non-slender sections & & & & \\
\hline All data & 1.22 & 0.13 & 88 & 1.03 \\
Austenitic & 1.30 & 0.11 & 51 & 1.12 \\
Duplex & 1.14 & 0.12 & 12 & 0.96 \\
Ferritic & 1.08 & 0.06 & 25 & 0.98 \\
\hline Slender sections & & & & \\
\hline All data & 1.49 & 0.18 & 140 & 1.17 \\
Austenitic & 1.59 & 0.15 & 60 & 1.30 \\
Duplex & 1.39 & 0.21 & 45 & 1.03 \\
Ferritic & 1.46 & 0.17 & 35 & 1.15 \\
\hline
\end{tabular}




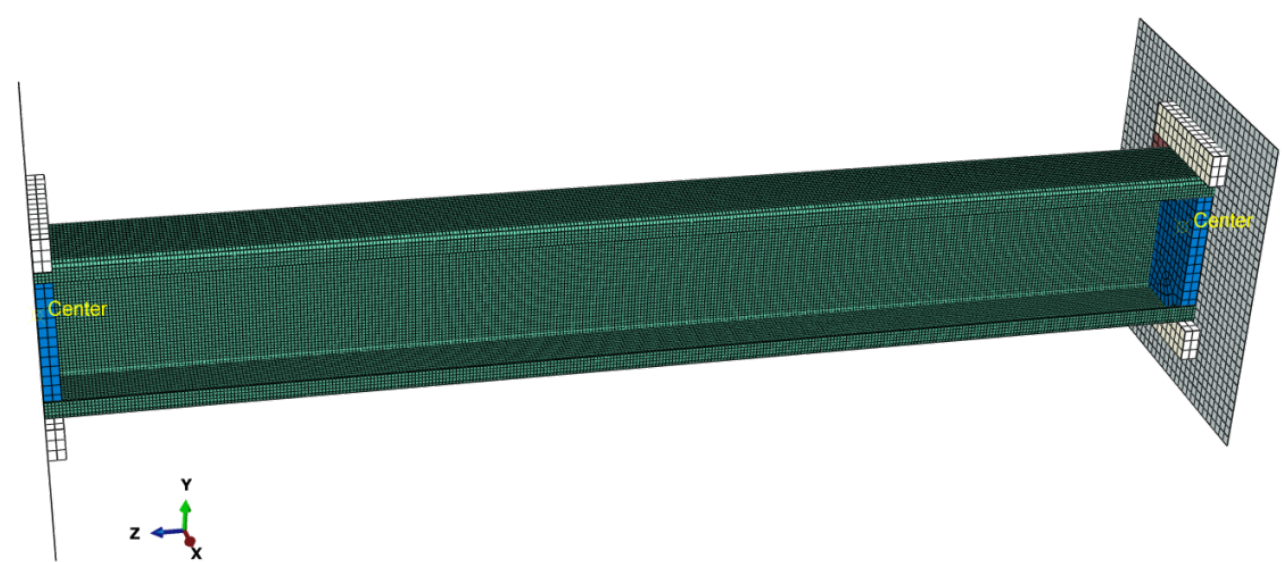

(a) Calibrated FE model of Rossi and Rasmussen's experiment [19]

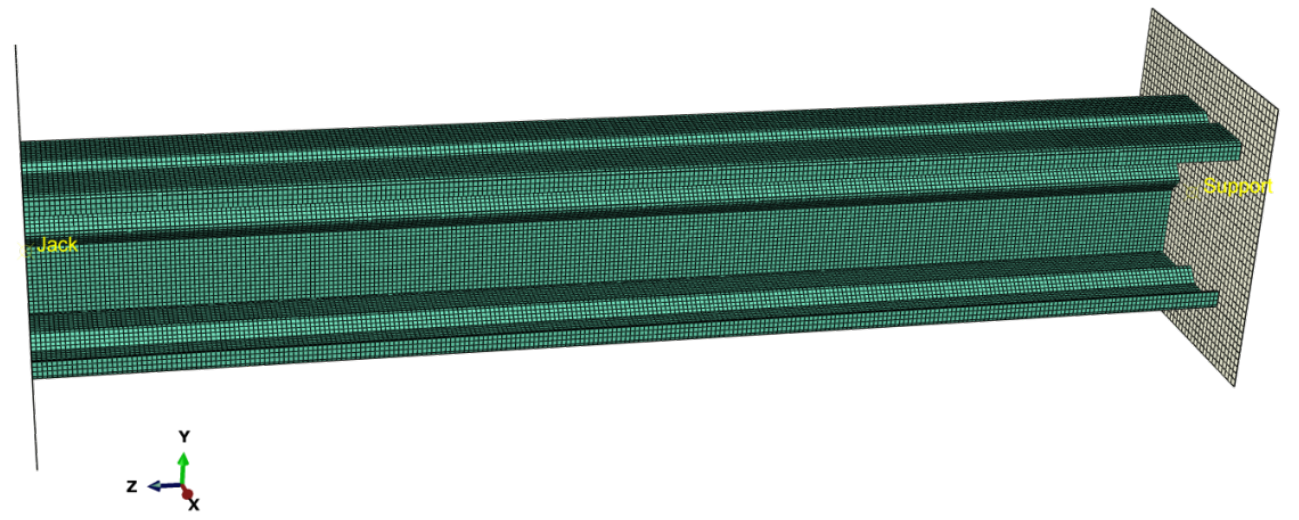

(b) Calibrated FE model of Lecce and Rasmussen's experiment [21]

Fig. 1 Geometry, boundary conditions and mesh of the calibrated FE models.

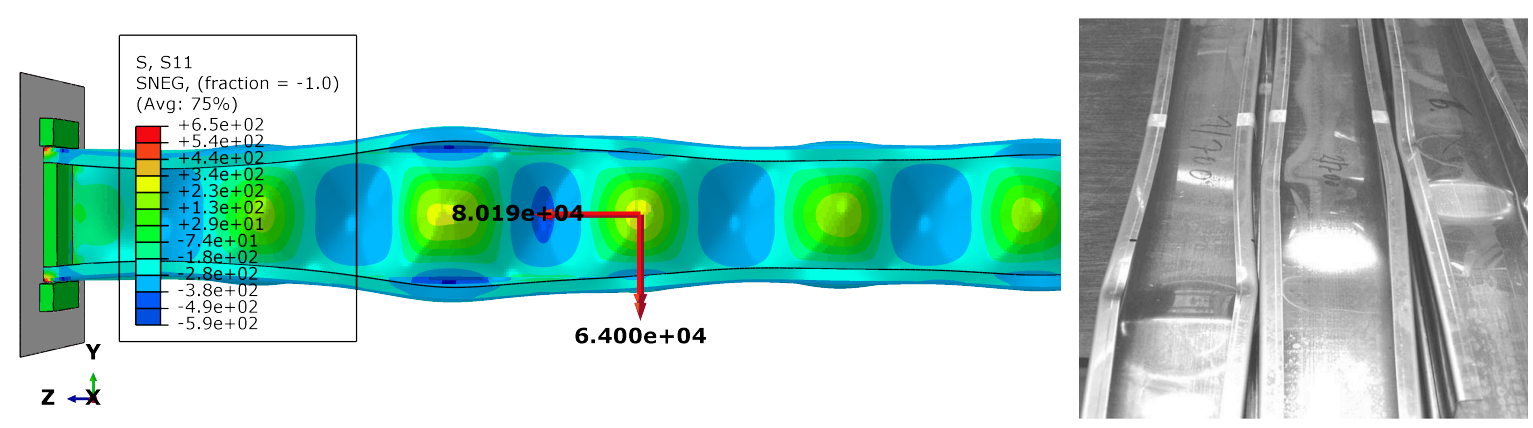

Fig. 2 FEM and experimental [19] buckling pattern of lipped channel column with a length of 900 $\mathrm{mm}$. 


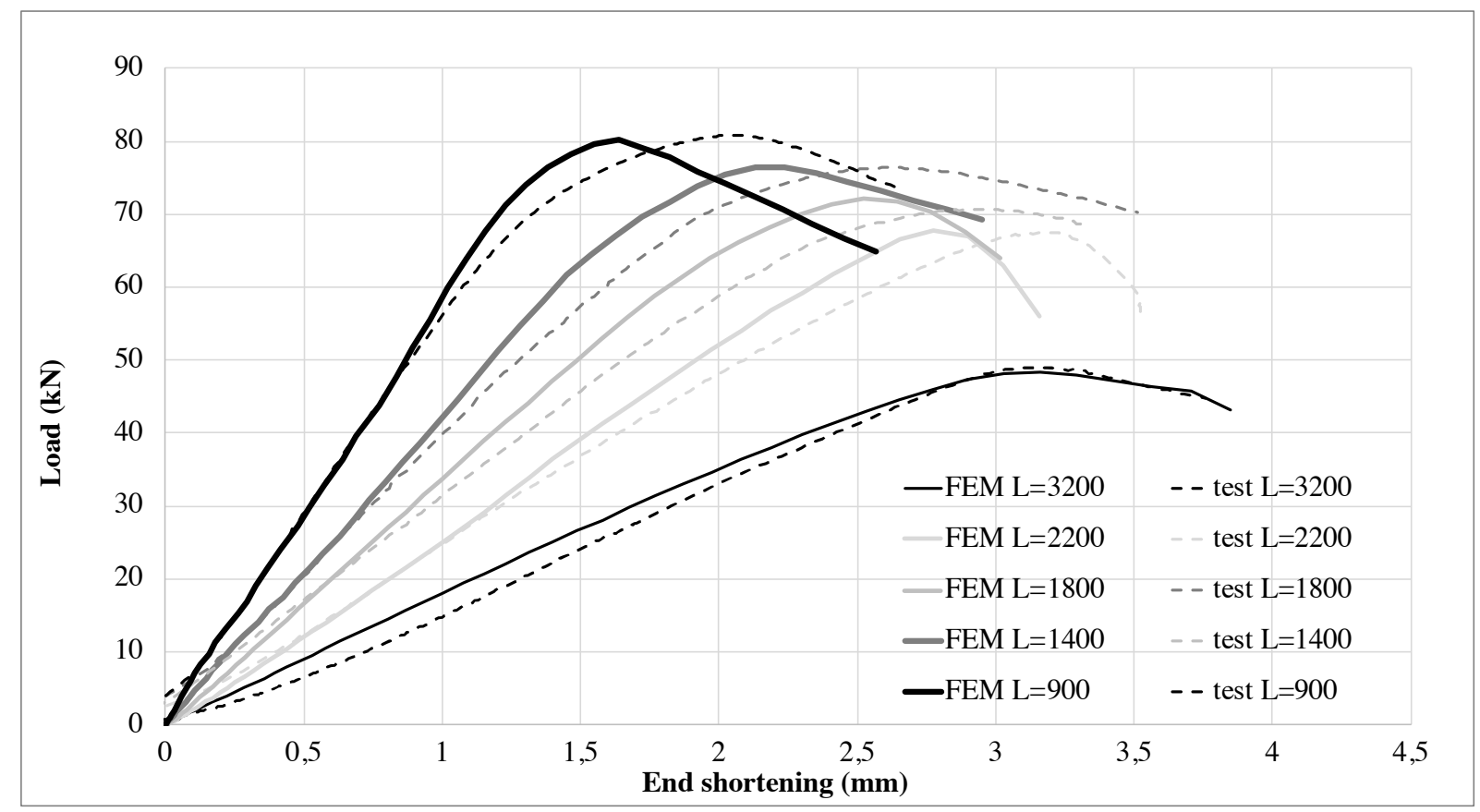

Fig. 3 Load versus end shortening - Comparison between experiments [19] and FEM results.

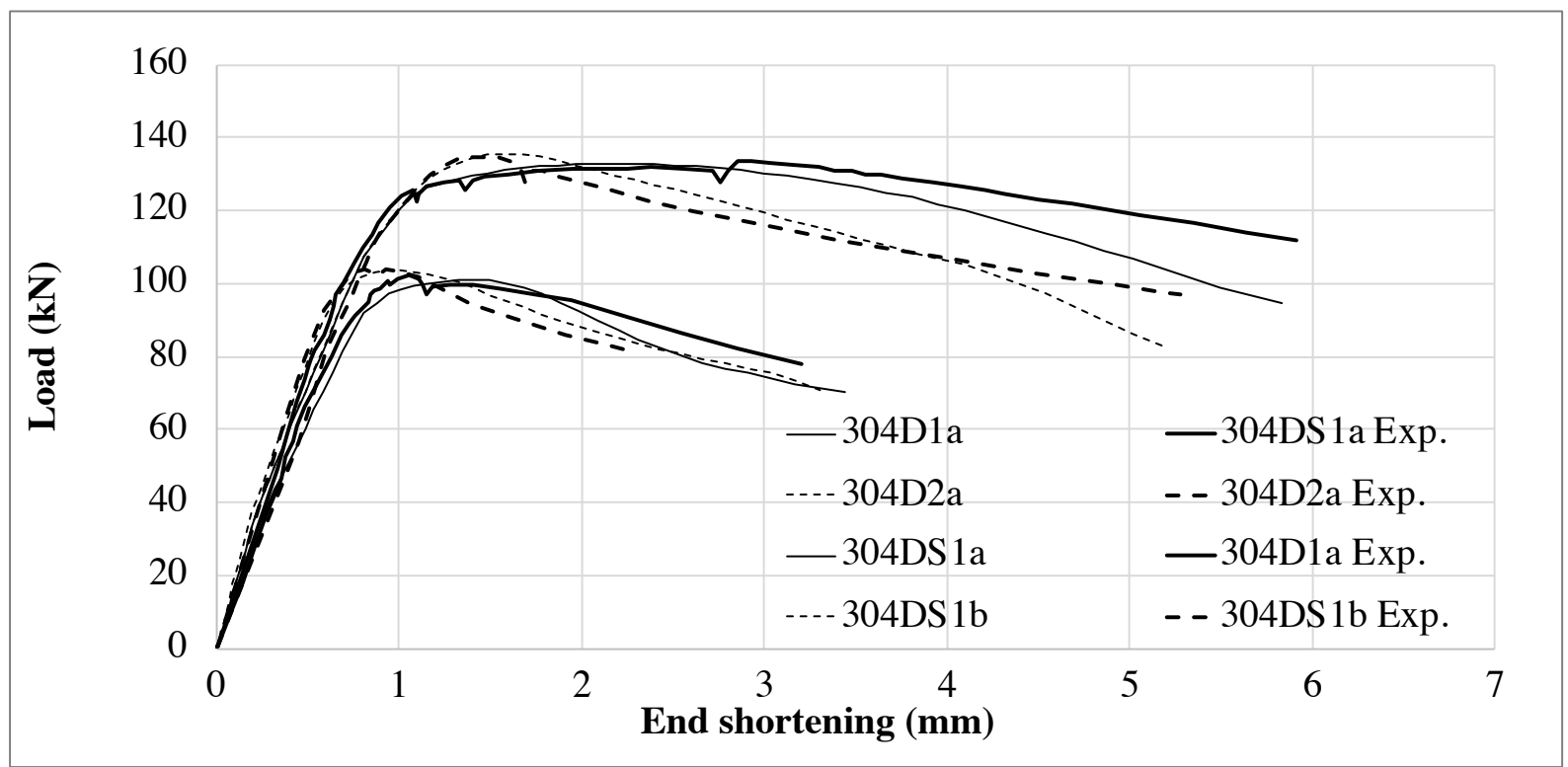

Fig. 4 Load versus end shortening recorded during the experiments of [21] compared to the FEM results. 

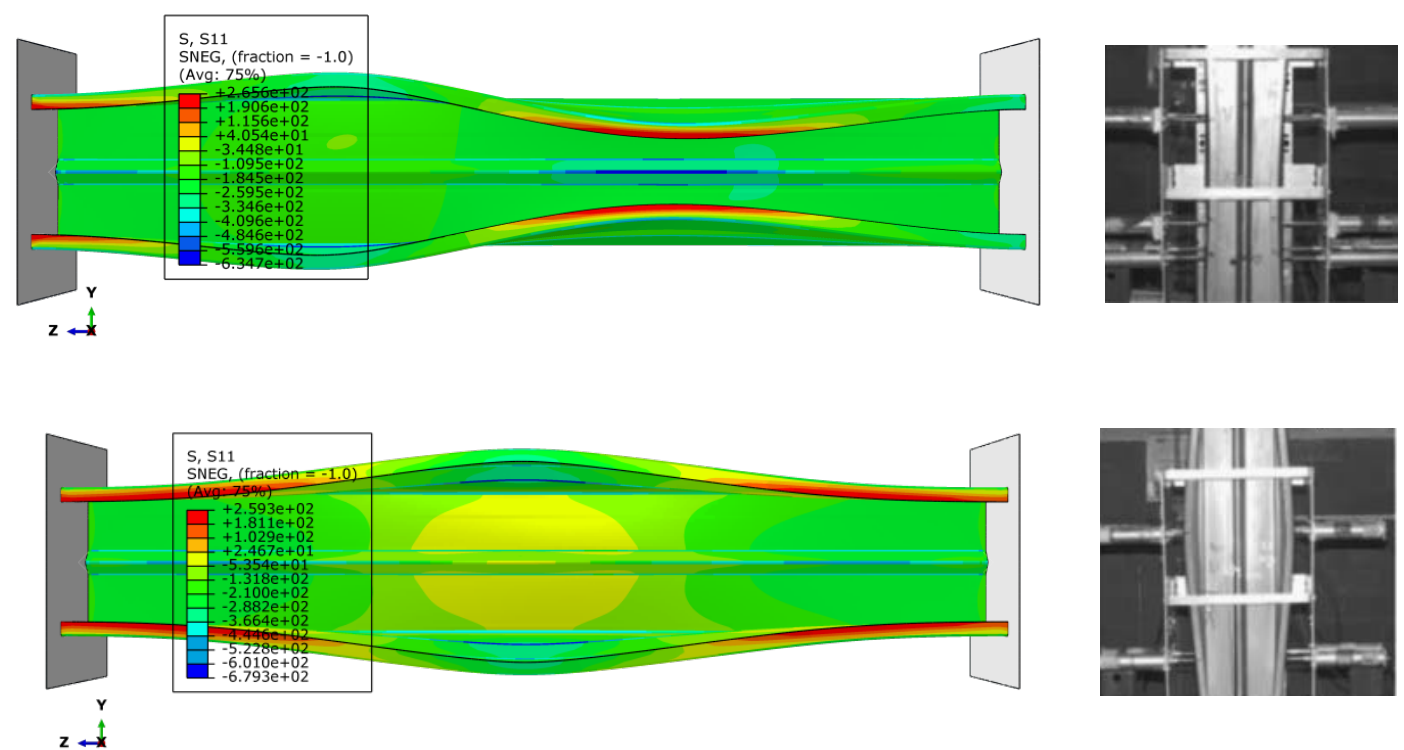

Fig. 5 FEM and Experimental [21] buckling pattern of lipped channel column.

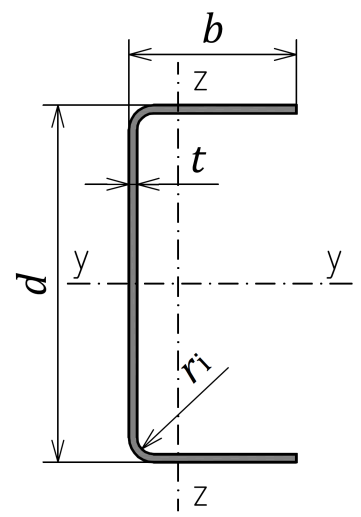

Fig. 6 Designations of cross-section geometry.
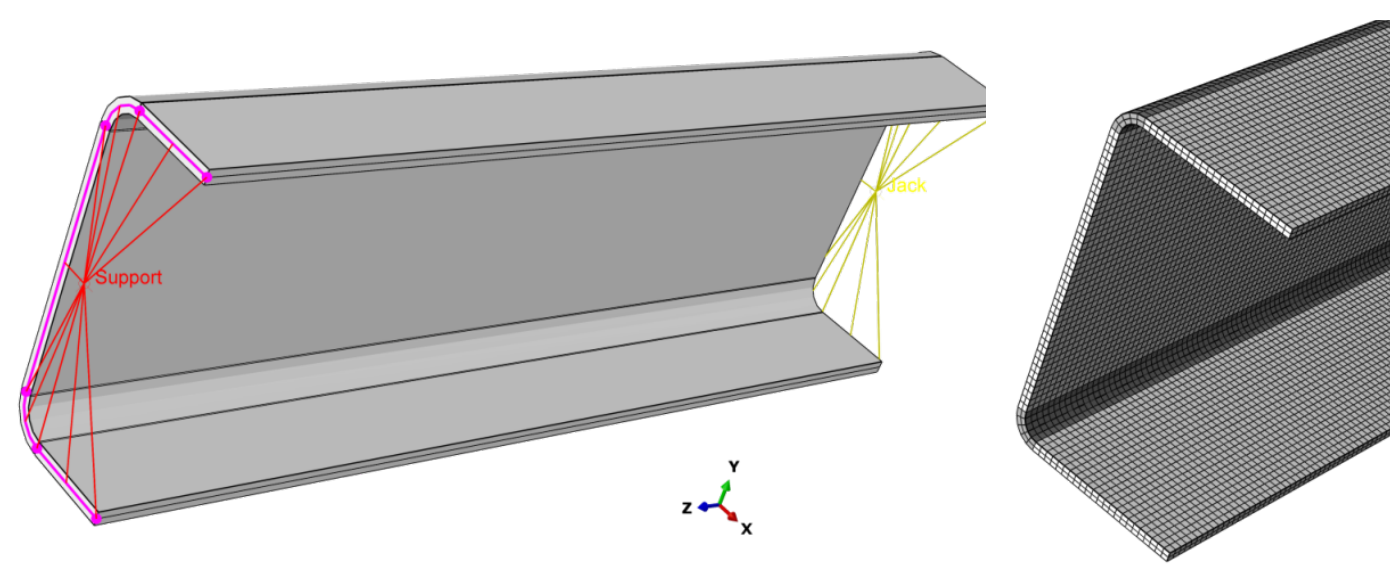

Fig. 7 Geometry and boundary conditions of one typical FE model. 


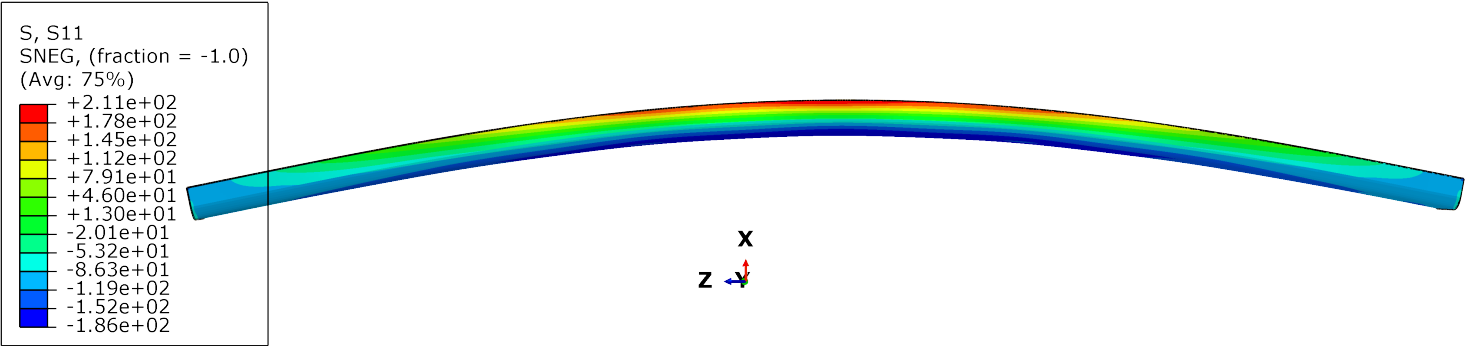

Fig. 8 FB about minor axis of FE column C100x40x6x1500 - duplex grade.

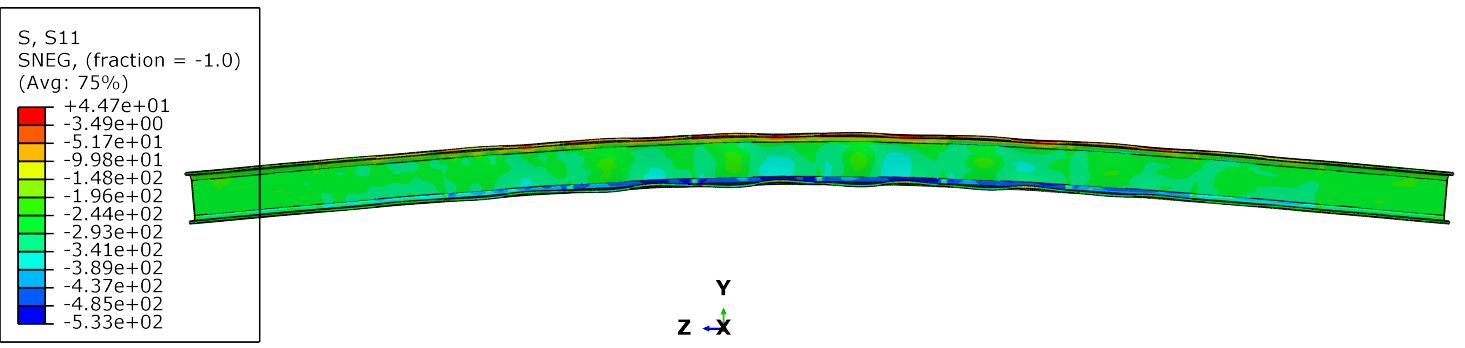

Fig. 9 FB about major axis of FE column C80x40x4x2000 - ferritic grade.

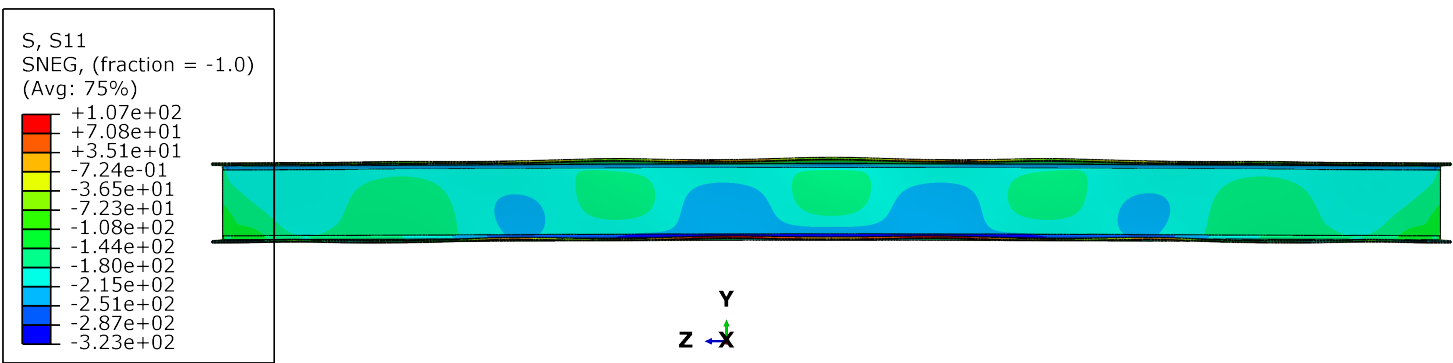

Fig. 10 FTB of FE column C160x90x4x2500 - austenitic grade.
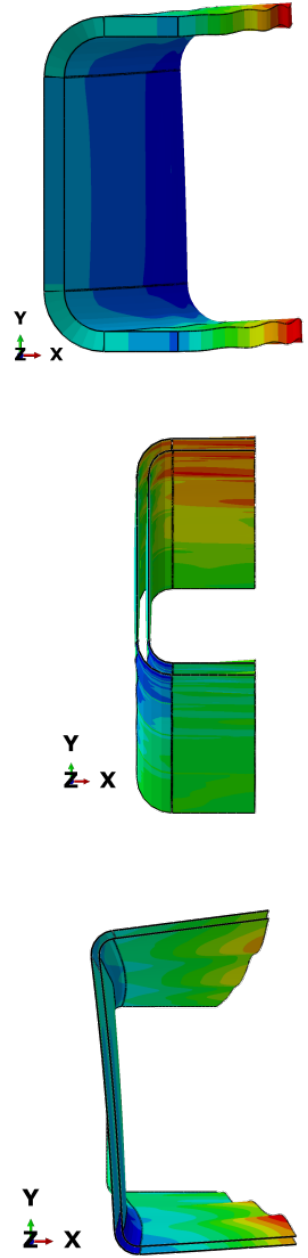


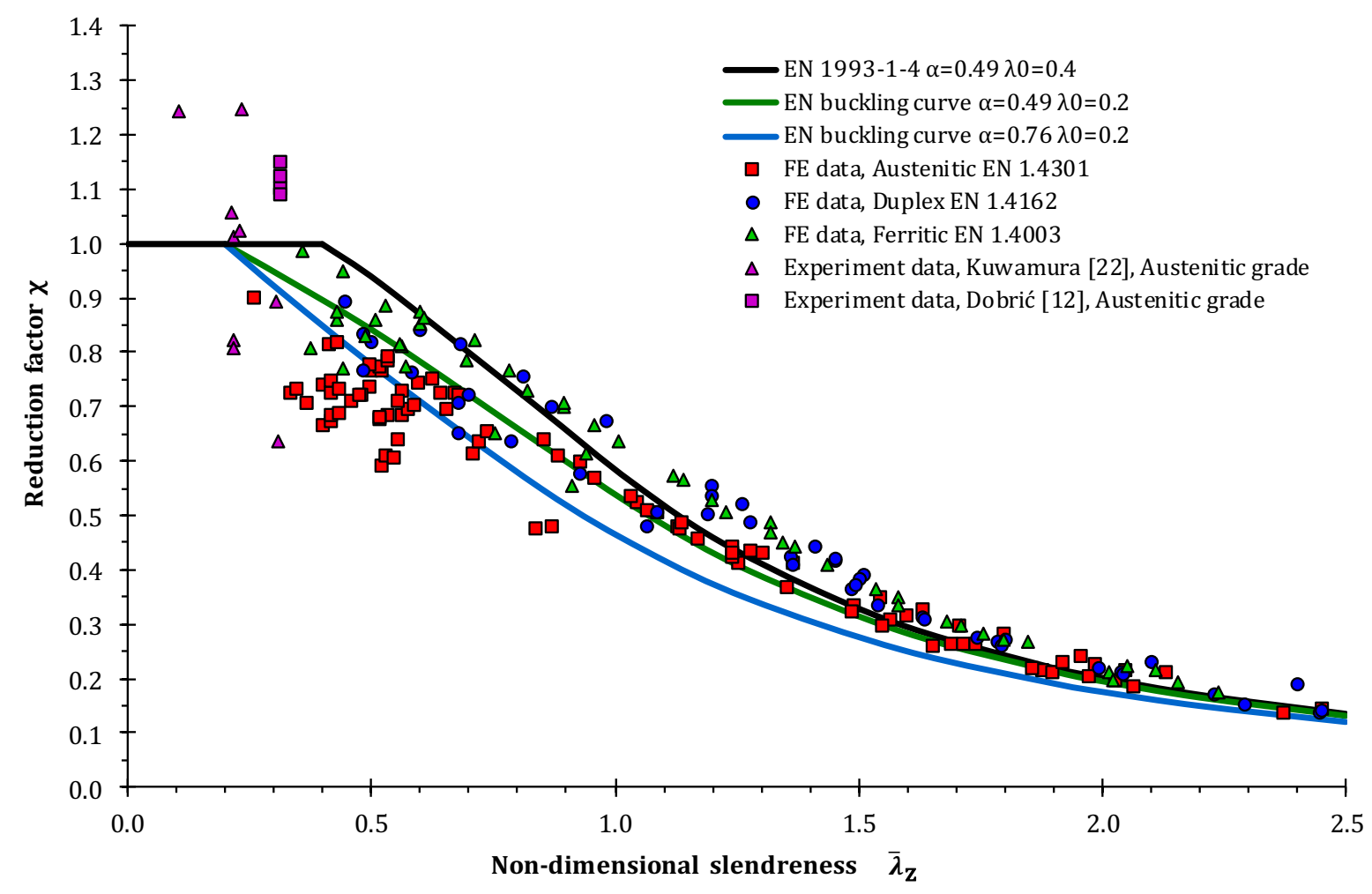

Fig. 11 Comparison between normalised FE results and EN 1993-1-4 curves for FB about minor axis.

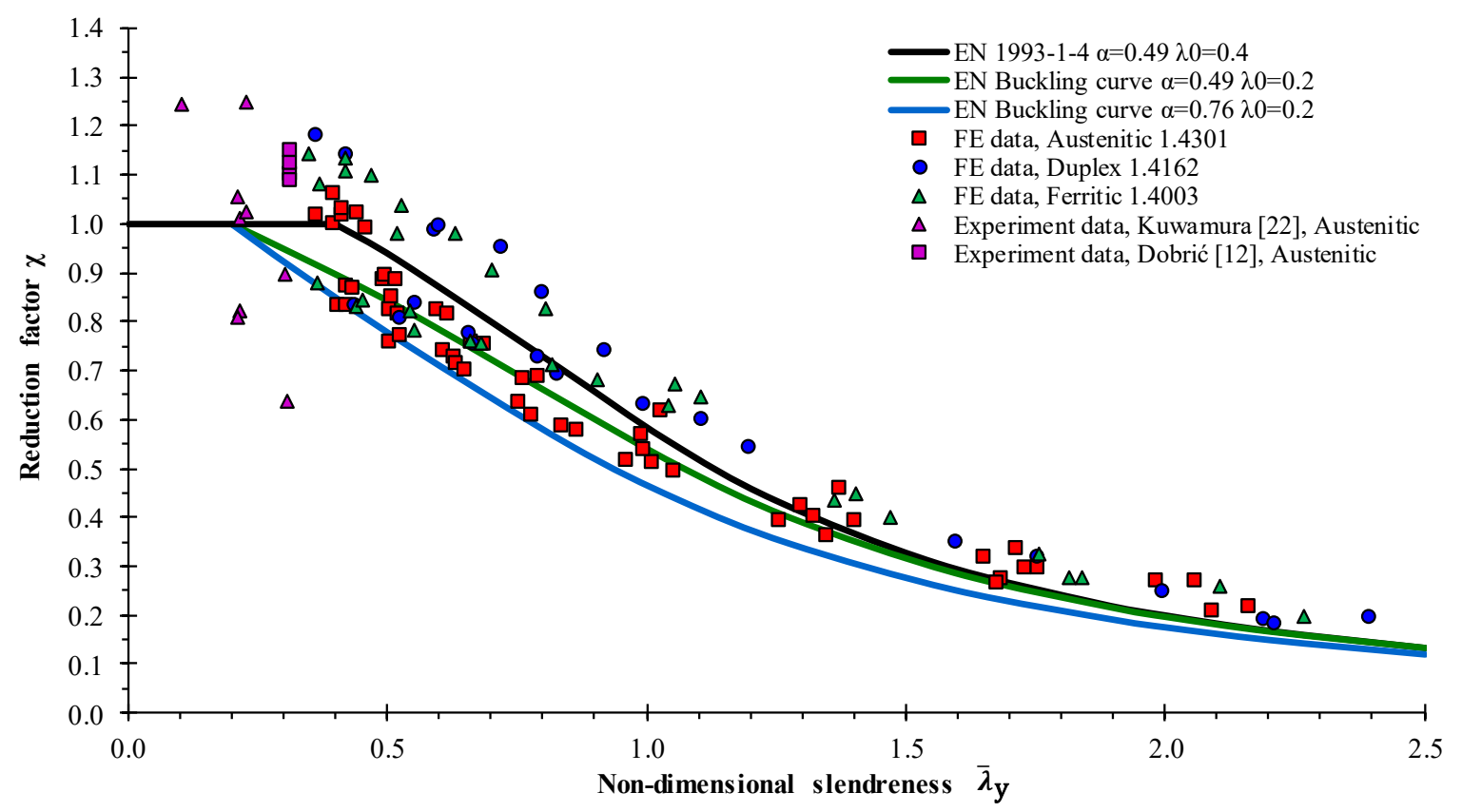

Fig. 12 Comparison between normalised FE results and EN 1993-1-4 for FB about major axis. 


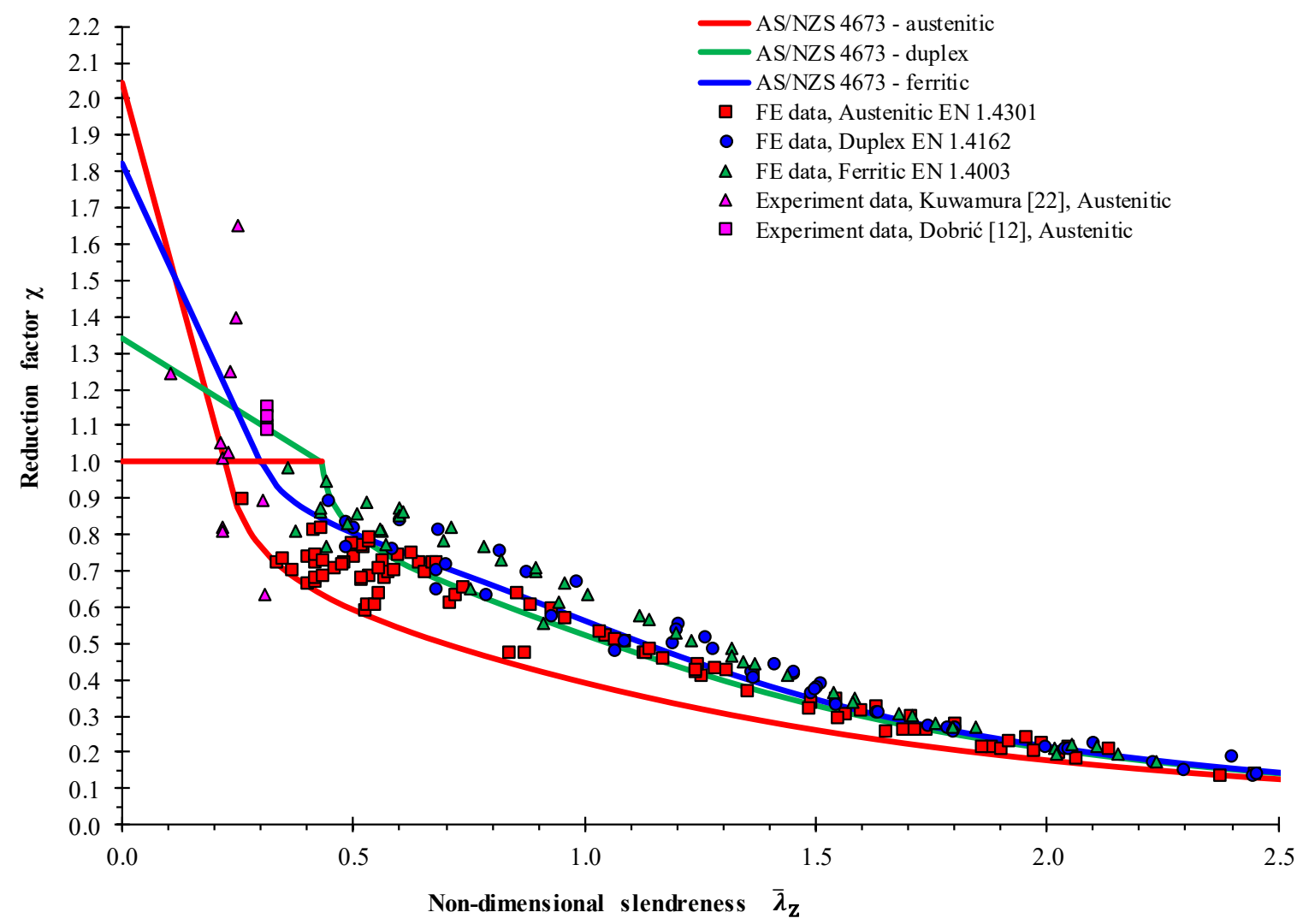

Fig. 13 Comparison between normalised FE results and AS/NZS 4673 curves for FB about minor axis. 


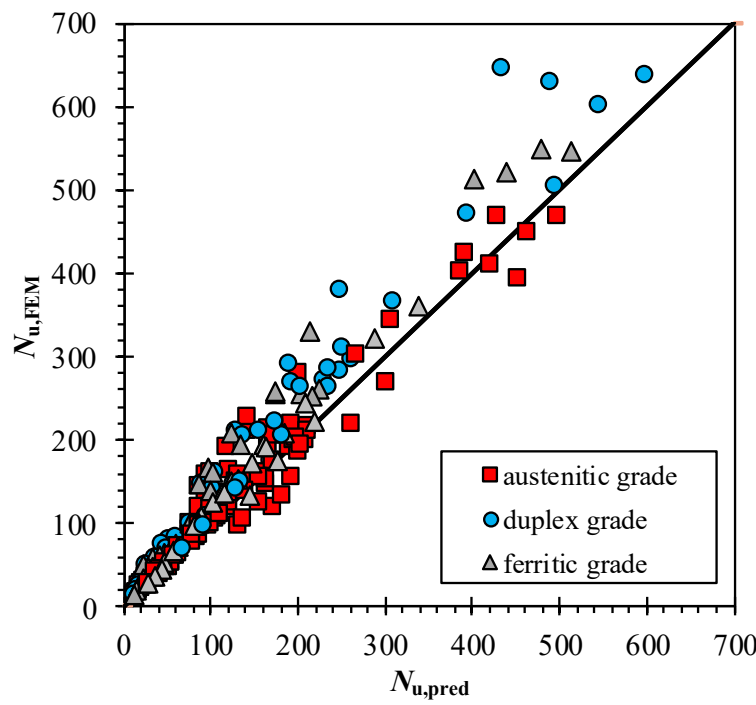

(a) FE data versus design data EN 1993-1-4 (buckling curve $\alpha=0.49 \bar{\lambda}_{0}=0.2$ ) / FB minor axis

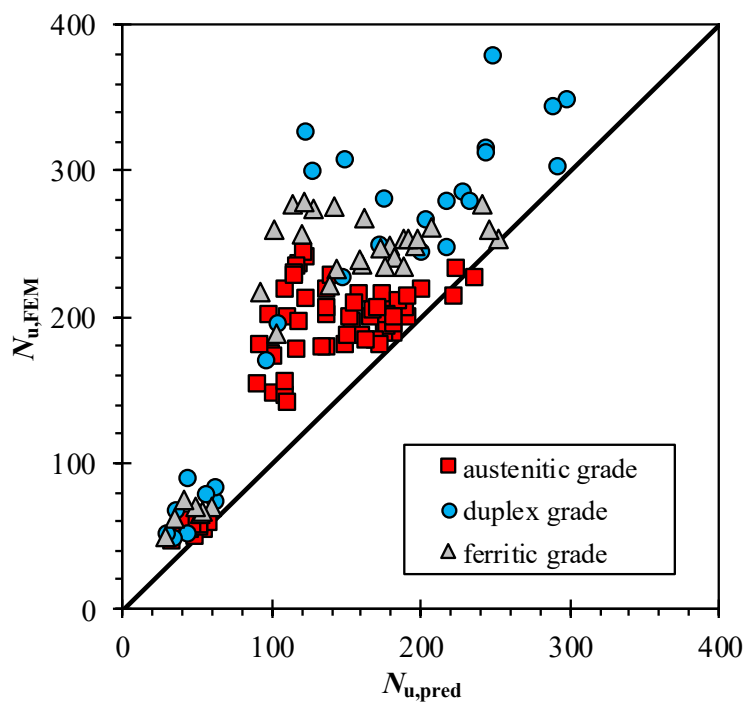

(c) FE data versus design data EN 1993-1-4 (buckling curve $\alpha=0.34 \bar{\lambda}_{0}=0.2$ ) / FTB

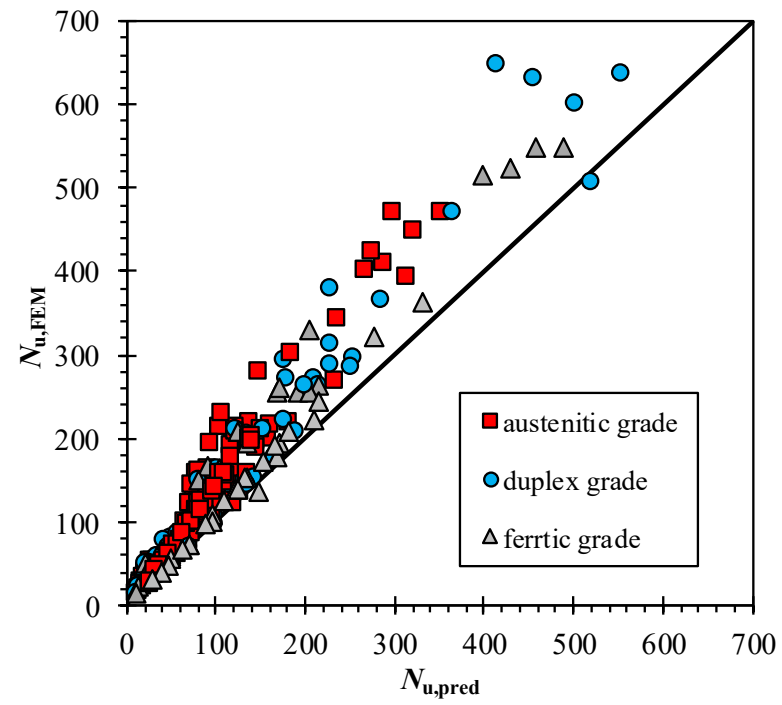

(b) FE data versus design data AS/NZS 4673 / FB minor axis

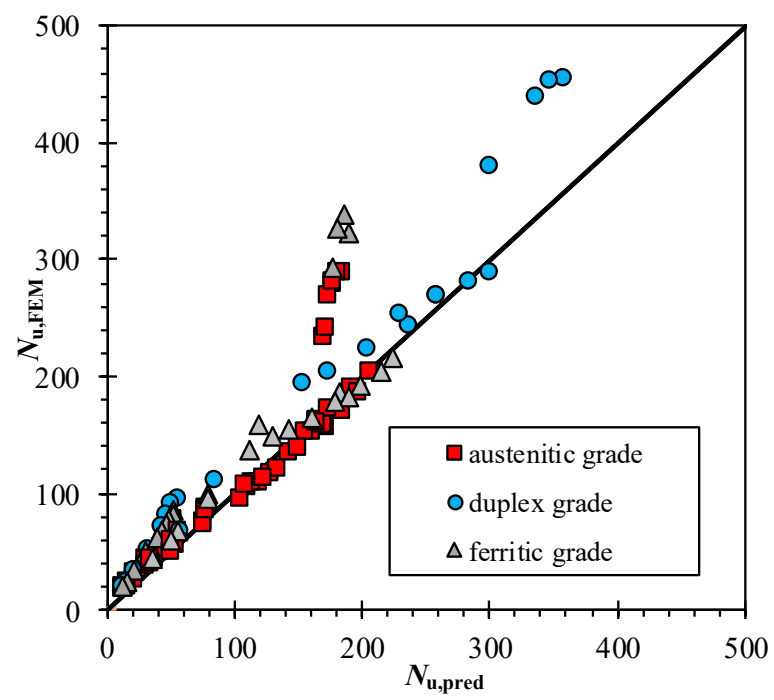

(d) FE data versus design data EN 1993-1-4 (buckling curve $\alpha=0.49 \bar{\lambda}_{0}=0.2$ ) / FB major axis

Fig. 14 Comparison of FE resistance with design resistance predictions for both slender and nonslender cross-sections. 